\title{
Chapter 3 \\ The Subductability of Continental Lithosphere: The Before and After Story
}

\author{
J.C. Afonso and S. Zlotnik
}

What I cannot create, I do not understand R. Feynman

\subsection{Introduction}

Although once believed that continental crust could not be subducted to significant depths due to its relative buoyancy, it is now accepted that relatively large sections of continental crust were subducted to depths $>100 \mathrm{~km}$ and exhumed at numerous locations worldwide (cf. Chopin 2003). The discovery of metamorphic diamonds (e.g. Kokchetav massif) and especially of pyroxene exsolution in garnets (e.g., Otrøy Island, Sulu metamorphic belt) further demonstrated the possibility of ultra-deep subduction of continental crust to depths $>250 \mathrm{~km}$ (cf. Chopin 2003; Ernst and Liou 2008, and references therein). Detailed thermobarometry and chronologic studies, and the fact that these ultra-high pressure (UHP) belts outcrop today, reflect the viability of effective exhumation mechanisms acting during the evolution of orogens. Analog experiments and numerical simulations of continental collision have demonstrated that both subduction of continental crust to depths of $\sim 100150 \mathrm{~km}$ and rapid exhumation are an integral part of an orogenic cycle (Gerya et al.

\footnotetext{
J.C. Afonso

Department of Earth and Planetary Sciences, GEMOC ARC Key Centre for Geochemical Evolution and Metallogeny of Continents, Macquarie University, North Ryde, Sydney, NSW 2109, Australia

e mail: juan.afonso@mq.edu.au

S. Zlotnik

School of Geosciences/School of Mathematical Sciences, Monash University, Clayton Campus, Melbourne, VIC 3800, Australia
}

2006; Warren et al. 2008; Yamato et al. 2008; Beaumont et al. 2009; Li and Gerya 2009). These studies have also shown that the final depth that continental material can reach and the style of exhumation are dependent on a number of factors, foremost among these are the convergence rate and the assumed rheology of both crust and mantle. The thermal structure of the incoming plate and erosion rates can also play a secondary role (Yamato et al. 2008; Li and Gerya 2009). The style of exhumation predicted by these studies include: pulse-like buoyant exhumation (dominated by either one or more pulses), syncollisional exhumation with two or more stages with distinct velocity, and continuous circulation in the critical wedge of an accretional prism. Of these, only the first two have been successful in reproducing HP-UHP P-Tpaths and crustal structures compatible with observations (Beaumont et al. 2009; Li and Gerya 2009).

In all studies of continental subduction, the relative buoyancy of the continental material with respect to the surrounding mantle (or crust) is a key factor. It ultimately controls the fate of the different subducted continental rocks (e.g. sedimentary, volcanic, igneous, etc.) and therefore the recycling of important chemical species such as large-ion lithophile elements (LILEs) and water (e.g., Ono 1998; Rapp et al. 2008). The way in which this positively buoyant material affects the dynamics of the collision depends strongly on the mechanical behavior (i.e., rheology) of the crustal units and on their bulk composition. If the crust is felsic and strong enough to maintain its mechanical coherence during subduction, it will effectively and continuously increase the positive buoyancy of the slab. Eventually, after a critical volume of continental crust has subducted, the slab reaches the state of "neutral buoyancy" and subduction stops (e.g., Ranalli et al. 2000). In contrast, if this felsic crust is relatively soft, it will be delaminated during subduction and thicken 
at shallow levels (e.g., Faccenda et al. 2009), making its contribution to increasing the positive buoyancy of the slab negligible. On the other hand, if more mafic crustal components are considered, as suggested for the lower crust by field and xenolith evidence (e.g., Rudnick and Gao 2003), eventual eclogitization of these components could increase the negative buoyancy of the slab, promoting subduction of crustal material. Similarly, the geometry and nature (volcanic vs non-volcanic) of the colliding passive margin should exert a non-negligible influence. It is evident therefore that the final configuration and evolution of the collision will depend on the interplay between these factors.

The possibility of continental material being subducted to depths pertaining to the transition zone, and perhaps even to the lower mantle, is supported by geochemical isotopic signatures in magmas erupted in island arcs presumably from source regions at depth $>300 \mathrm{~km}$ (Workman et al. 2004). Another set of evidence for deep subduction is provided by experimental data at extremely high pressures (e.g., Irifune et al. 1994; Dobrzhinetskaya and Green 2007; Rapp et al. 2008; Zhai and Ito 2008; Wu et al. 2009). These studies indicate that a "depth of no return" for continental derived materials may exist at around 8.5 $9 \mathrm{GPa}$, where dense silicates start to form (e.g., Irifune et al. 1994; Dobrzhinetskaya and Green 2007; Rapp et al. 2008; Zhai and Ito 2008). Irifune et al. (1994) hypothesized about the settings in which subduction of continental derived materials would occur. These authors proposed active ocean ocean and ocean continent subduction zones as one potential environment, where significant amounts of sediments are being subducted into the mantle (e.g., Clift and Vannucchi 2004). The other, arguably more important, is along zones of continental collision (arc continent and continent continent), where large pieces of continental crust could be subducted. However, the actual amount of continental material that can be subducted below the point of no return and its final fate has never been assessed with coupled thermomechanicalthermodynamic numerical models.

This paper attempts to provide new insights into the large-scale evolution of an arc continent collision from the subduction of normal oceanic lithosphere to the cease of subduction. We use 2D fully dynamic thermomechanical-thermodynamic numerical simulations and a new thermodynamic database that includes all major phases relevant to deep subduction of continental material. Particular emphasis is put on the self-consistent evolution of convergence velocities (i.e., no velocity boundary conditions imposed) and on the roles of compositional heterogeneities, rheological properties, and thermal structures of the subducting plate.

\subsection{Methods and Numerical Setup}

In the following three sections we briefly describe the methodology and numerical setup used in this study. The interested reader in these topics should refer to the appendices, where we provide a detailed explanation of all the numerical strategies and their implementations into our code.

\subsubsection{Bulk Properties of Rocks}

When direct comparisons with geological, geochemical, and geophysical evidence are sought, numerical simulations need to include realistic thermophysical properties for all the materials composing the model. In recent years, particular attention has been given to the self-consistent combination of mineral physics and thermodynamic calculations into fluid dynamical simulations of the Earth (e.g., Gerya et al. 2006; Li and Gerya 2009; Tirone et al. 2009; Nakagawa et al. 2009; Yamato et al. 2007). This approach has two important advantages over other standard methods. One is that it maximizes the internal consistency of the system by "tightening" together all physical parameters and governing equations through a thermodynamic model. Therefore, a given change in density due for instance to a change in P-T conditions is also reflected in appropriate (thermodynamically consistent) changes in all other parameters (e.g., heat capacity, compressibility, etc.). The other advantage is that it allows realistic modelling of metamorphic reactions driven by the dynamics of the system. These include not only solid state reactions but also hydration/dehydration reactions, partial melting, and melt-solid interactions. This in turn is essential when comparing real petrological and geophysical observables with simulation results (Gerya et al. 2006; Beaumont et al. 2009; Li and Gerya 2009). 
Following previous pioneering works (e.g., Sobolev and Babeyko 2005; Gerya et al. 2006) we couple our thermo-mechanical solvers with thermodynamic data sets that account for all metamorphic reactions and phase changes (see Appendix A). Relevant bulk properties (e.g., density, thermal expansion coefficient, etc.) are calculated a priori for different compositions, water contents, and P-T range of interest, and saved in "look-up" tables that are read by the thermomechanical solver during execution. One of the main differences with previous models is that while they make use of thermodynamic databases strictly suitable at pressures $\lesssim 3 \mathrm{Gpa}$, we use an augmented-modified version of the Holland and Powell (1998) database (revised in 2002) valid up to $25 \mathrm{GPa}$ that includes all major phases obtained in UHP experiments on compositions relevant to the continental crust (e.g., Irifune et al. 1994; Wu et al. 2009; Ono 1998; Zhai and Ito 2008; Rapp et al. 2008). Since it has been suggested that some dense silicates such as K-hollandite $\left(\mathrm{KAlSi}_{3} \mathrm{O}_{8}\right)$ and CAS $\left(\mathrm{CaAl}_{4} \mathrm{Si}_{2} \mathrm{O}_{11}\right)$ could be responsible for the recycling of continental material and important trace elements into the transition zone or lower mantle (Zhai and Ito 2008; Rapp et al. 2008; Wu et al. 2009), using a database that correctly predicts phase relations at such conditions is of particular relevance. See Appendix A.6 for details on the thermodynamic formalism and database used in this study.

\subsubsection{Starting Materials}

Our reference starting model is shown in Fig. 3.1. It is composed of five main domains, namely the continent sensu stricto, the passive margin, the oceanic domain, the arc domain, and the sublithospheric mantle. Each of these domains is characterized by a compositional and thermal structure based on real case examples. In the case of the continental, oceanic, and passive margins domains, our reference model is based on the integrated geophysical-petrological model of Fernàndez et al. (2010) across the Namibian volcanic margin. In the case of the 2D arc crustal structure, we use the present-day structure of the Mariana arc as a proxy (Takahashi et al. 2008). The continental domain is made of a granodioritic upper crust, a mafic granulitic lower crust, a depleted shallow lithospheric mantle, and a deep (less depleted) lithospheric mantle. The oceanic domain is composed of a thin layer of pelagic sediments, a basaltic upper crust, a gabbroic lower crust, a depleted shallow lithospheric mantle, and a deep (less depleted) lithospheric mantle. The reference passive margin includes some layers from the continental and oceanic domains plus two additional layers: a silicoclastic sedimentary wedge (miogeoclinal prism) and a gabbroic underplating body. The arc structure includes a tonalitic upper/middle crust, a gabbroic lower crust, a depleted shallow lithospheric mantle, and a deep lithospheric mantle. The bulk composition of all lithologies used in our models are listed in Tables 3.1 and 3.2. Rheological parameters are listed in Table 3.4 and reference strength envelopes for the initial conditions are shown in Fig. 3.2.

The degree of hydration of the incoming crustal units is as follows: pelagic sediments contain 7.36 wt\% water (Rapp et al. 2008), oceanic upper (metabasalt) and lower (metagabbros) crusts contain 2.96 and $1.97 \mathrm{wt} \%$ water, respectively, to represent the effects of hydrothermal alteration (Carlson 2003). The sediments making up the miogeoclinal prism in the passive margin contain an initial water content of $7.55 \mathrm{wt} \%$. For the serpentinized shallow upper mantle underneath the oceanic crust we assume a generous serpentinization degree of $20 \%$, equivalent to an original water content of $2.6 \mathrm{wt} \%$ (Schmidt and Poli 1998). The entire continental crust is assumed to be dry, while the lower crust of the arc contains $2 \mathrm{wt} \%$ of water (Takahashi et al. 2008). Note that in this work we use "water" for pure $\mathrm{H}_{2} \mathrm{O}$, although the actual aqueous fluid in a subduction environment may be different (i.e., silica-rich).

\subsubsection{General and Boundary Conditions}

The mechanical boundary conditions in our numerical domain are periodic on the lateral sides and free-slip at the top and bottom (Fig. 3.1a). Importantly, we do not impose velocity boundary conditions and therefore the dynamics of our simulations is controlled entirely by the balance between internal forces (e.g., buoyancy, shear resistance, etc.). The resolution varies between models, but typical nodal spacings are between 5.0 and $2.2 \mathrm{~km}$, with around 4.6 and 15 million markers, respectively. 


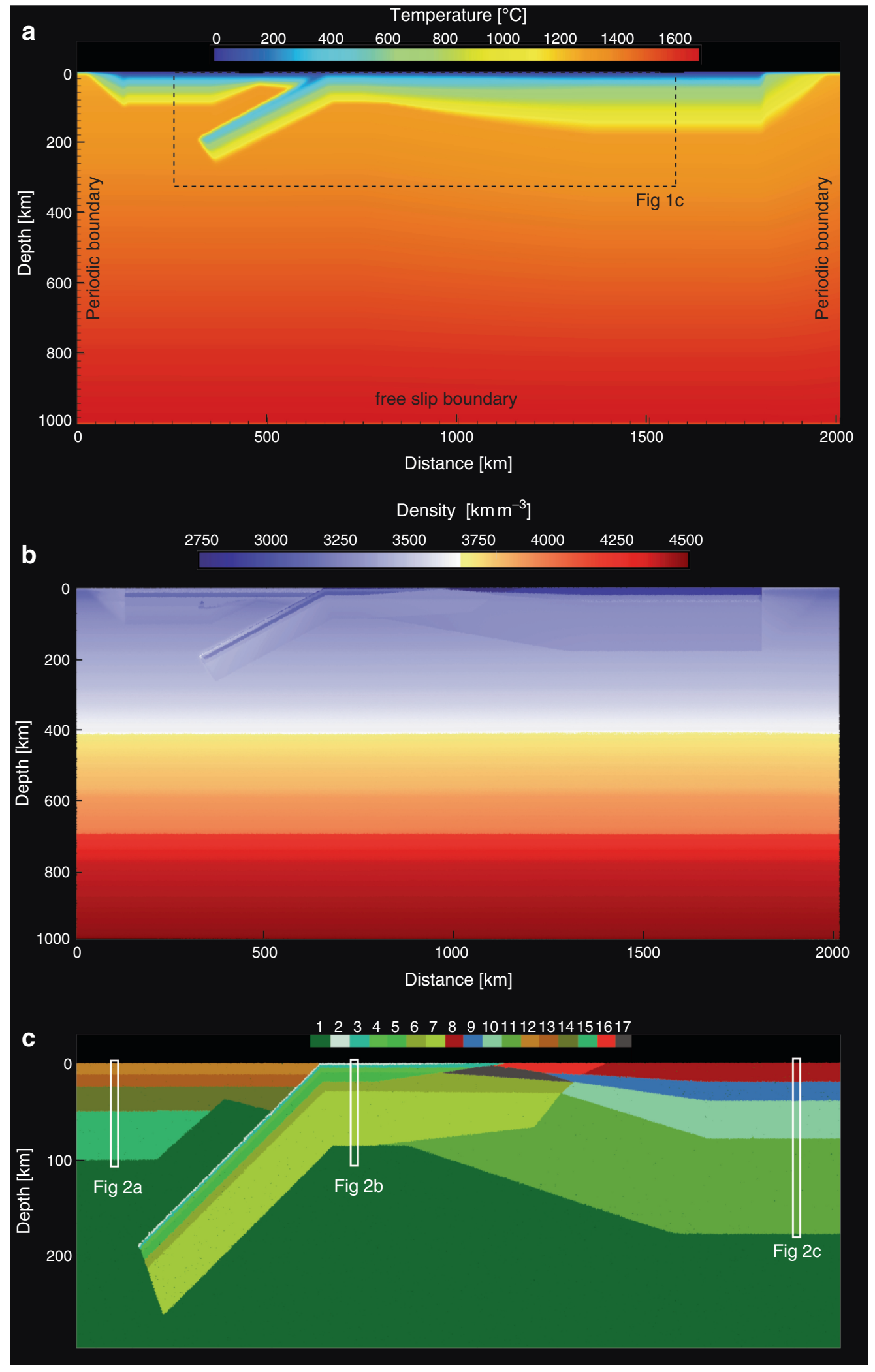


Table 3.1 Model bulk rock compositions for crustal layers [wt $\%$ ]

\begin{tabular}{lccclrrrrr}
\hline Composition & Cont. UC & \multicolumn{1}{c}{ Cont LC } & Arc MC & Oce. UC & Oce. LC & Pelag. sed. & Prism sed. & Underplating $^{\mathrm{h}}$ & Cont LC felsic $^{\mathrm{i}}$ \\
$\mathrm{SiO}_{2}$ & 65.81 & 53.52 & 65.80 & 48.99 & 52.58 & 54.32 & 60.69 & 53.63 & 63.67 \\
$\mathrm{TiO}_{2}$ & 0.66 & 0.82 & 0.48 & 1.27 & 0.59 & 0.84 & 0.64 & 0.60 & 0.69 \\
$\mathrm{Al}_{2} \mathrm{O}_{3}$ & 15.31 & 16.94 & 15.70 & 14.89 & 13.83 & 17.42 & 12.34 & 14.11 & 15.04 \\
$\mathrm{FeO}$ & 5.34 & 8.59 & 4.49 & 9.86 & 6.74 & 7.79 & 5.40 & 6.88 & 6.04 \\
$\mathrm{MgO}$ & 2.82 & 7.26 & 1.82 & 7.56 & 12.48 & 3.08 & 2.57 & 12.73 & 3.60 \\
$\mathrm{CaO}$ & 4.10 & 9.61 & 5.03 & 11.26 & 10.52 & 1.54 & 6.17 & 10.73 & 5.26 \\
$\mathrm{Na}_{2} \mathrm{O}$ & 3.31 & 2.66 & 3.91 & 2.70 & 1.20 & 3.93 & 2.52 & 1.22 & 3.40 \\
$\mathrm{~K}_{2} \mathrm{O}$ & 2.65 & 0.61 & 0.79 & 0.49 & 0.09 & 3.73 & 2.11 & 0.09 & 2.31 \\
$\mathrm{H}_{2} \mathrm{O}$ & $0 *$ & $0 *$ & 1.99 & 2.96 & 1.97 & 7.36 & 7.55 & $0 *$ & 0 \\
\hline
\end{tabular}

*Initial water content, these values change as the materials are hydrated/dehydrated

${ }^{a}$ Estimated using $70 \%$ of upper crust composition and 30\% of middle crust composition from Rudnick and Gao (2003)

${ }^{\mathrm{b}}$ From Rudnick and Gao (2003)

${ }^{\mathrm{c}}$ Recast from the middle (tonalitic) crust composition of Takahashi et al. (2008)

${ }^{\mathrm{d}}$ Recast from the normal MORB composition in Schilling et al. (1983)

${ }^{\mathrm{e}}$ Recast from Behn and Kelemen (2003)

${ }^{\mathrm{f}}$ Recast from the MAG 1 composition of Rapp et al. (2008)

${ }^{g}$ Recast from the GLOSS composition of Plank and Langmuir (1998)

${ }^{\mathrm{h}}$ Same as Oce. LC but dry

${ }^{\mathrm{i}}$ Middle crust composition of Rudnick and Gao (2003)

Table 3.2 Model bulk rock compositions for mantle domains [wt\%]

\begin{tabular}{lcccc}
\hline Composition & Sublith. Mantle & Harzburg. Mantle & Tecton mantle $^{\mathrm{c}}$ & Cont. upp. Mantle $^{\mathrm{d}}$ \\
$\mathrm{SiO}_{2}$ & 45.34 & 43.28 & 44.84 & 45.60 \\
$\mathrm{TiO}_{2}$ & 0.00 & 0.00 & 0.00 & 0.00 \\
$\mathrm{Al}_{2} \mathrm{O}_{3}$ & 4.53 & 1.11 & 2.63 & 1.79 \\
$\mathrm{FeO}$ & 8.16 & 7.26 & 8.28 & 7.31 \\
$\mathrm{MgO}$ & 38.08 & 47.62 & 41.51 & 43.51 \\
$\mathrm{CaO}$ & 3.53 & 0.61 & 2.52 & 1.74 \\
$\mathrm{Na}_{2} \mathrm{O}$ & 0.36 & 0.12 & 0.18 & 0.05 \\
$\mathrm{~K}_{2} \mathrm{O}$ & 0.03 & 0.00 & 0.03 & 0.00 \\
$\mathrm{H}_{2} \mathrm{O}$ & 0.00 & 0.00 & 0.00 & 0.00 \\
\hline
\end{tabular}

${ }^{\mathrm{a}}$ Recast from McDonough and Sun (1995)

${ }^{\mathrm{b}}$ Recast from the average Slave xenoliths composition in Afonso et al. (2008a)

${ }^{\mathrm{c}}$ Recast from the average Tecton peridotite composition in Afonso et al. (2008a)

${ }^{\mathrm{d}}$ Representative average of the first $100 \mathrm{~km}$ of continental lithospheric mantle from Fernàndez et al. (2010)

We assume incomplete hydration of mantle lithologies in the mantle wedge due to the channelization of fluids (Hyndman and Peacock 2003), which is not explicitly included in our simulations. We therefore assign a maximum water content of $4 \%$, in agreement with inferences from seismic studies (Hyndman and Peacock 2003; Carlson and Miller 2003).
As subducted lithologies reach saturation conditions, water is released through dehydration reactions (cf. Tatsumi and Eggins 1995) and starts its migration towards the surface (see details in Appendix A.5). Eventually, it may reach lithologies at undersaturated conditions (typically in the mantle wedge) that will incorporate all or some of this water by hydration
Fig. 3.1 (a) Initial thermal structure and mechanical boundary conditions of our reference model. The dashed rectangle refers to the zoom in Fig. 1c. (b) Initial density structure of the reference model. (c) The different colours indicate rock types (different bulk compositions): 1 = Sublithospheric mantle, $2=$ pelagic sediments, 3 = oceanic upper crust, $4=$ oceanic lower crust, $5=$ serpentinized mantle, $6=$ harzburgitic (depleted) mantle, 7 = deep oceanic lithospheric mantle (Tecton composition),
$8=$ upper continental crust, $9=$ lower continental crust, $10=$ harzburgitic (depleted) shallow continental mantle, $11=$ deep continental lithospheric mantle (Tecton composition, $12=$ arc upper crust, $13=$ arc lower crust, $14=$ arc shallow mantle (harzburgitic), 15 = deep arc mantle (Tecton composition), $16=$ sediments of the miogeoclinal prism, $17=$ underplating. Refer to Tables 1 and 2 for compositions. 


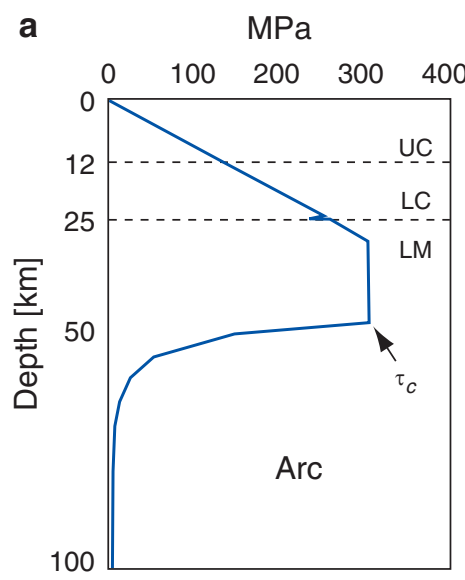

b

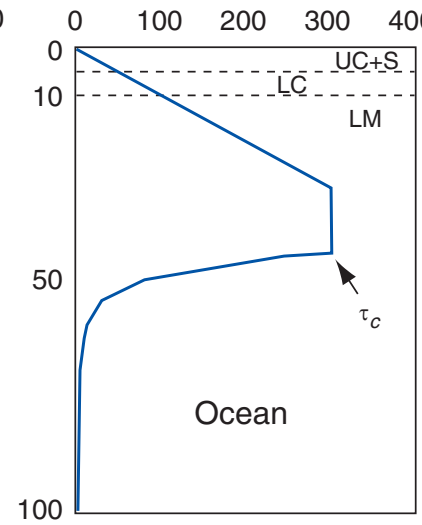

c

$\mathrm{MPa}$

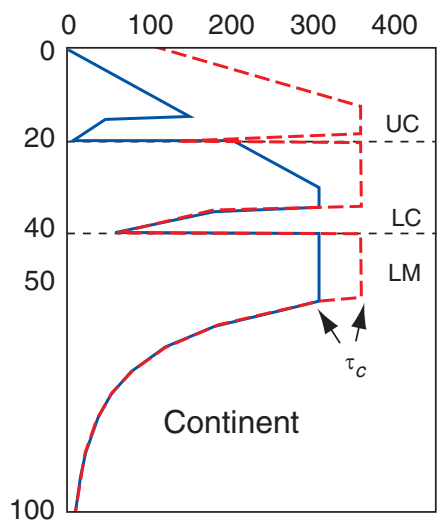

Fig. 3.2 Representative strength envelopes for the arc, ocean and continental domains ( strain rate $=10^{-16} \mathrm{~s}^{-1}$ ). The solid blue and dashed red lines in the continental domain indicate two

reactions. If not all of the incoming water is consumed by unsaturated lithologies, the remaining water keeps being advected until it is totally consumed in hydrating other parts of the model or until it reaches the surface. Figure 3.3 shows the water content (i.e., bound water in hydrous assemblages) in four important lithologies as a function of temperature, pressure, and initial bulk water content.

Melting of the mantle is modelled as batch melting (Appendix A.4), including the extraction of water from partially molten rocks through an appropriate bulk partition coefficient. The amount of melt extracted from mantle parcels is tracked through the simulation and used to compute depletion effects on the bulk density and solidus temperature of the residue (Appendix A.4). In the present work we do not model the chemical interaction between melts and the solid mantle (e.g., metasomatic silica enrichment).

\subsection{Results}

In this section we summarize the main results of a series of 80 numerical simulations of continental subduction. First we describe the evolution and general aspects of a reference model that satisfy a number of geophysical and geological evidence, in which the only kinematic boundary condition is a zero horizontal velocity in the far-end of the continental plate (i.e., fixed far-end). This is done in order to simulate trench end member cases used in our simulations (strong vs soft crust). $\tau_{\mathrm{c}}$ is the critical yield stress used to simulate high pressure failure. See text for details.

retreat in our reference model, but we relax this condition in subsequent simulations. Secondly, we analyze a number of factors with the potential to exert an influence on the dynamics of the system, and discuss their implications for interpreting arc continent collisional settings.

\subsubsection{The Reference Model}

The evolution of the reference model is characterized by four main stages (Fig. 3.4). The first stage is the verticalization of the slab under the force of gravity. Since the initial angle of subduction is considerably shallow, this stage is characterized by fast velocities in the sublithospheric mantle (Figs. 3.4a c and 3.5). Dipslip motion along the interface between the two plates (i.e., subduction channel) initiates during this stage, in which the convergence velocity between the plates steadily increases until a quasi-stable oceanic subduction configuration is reached (Fig. 3.5). During thisquasi-stable subduction stage the magnitude of both plate and convecting mantle velocities remains almost constant (Stage 2 in Fig. 3.5), reflecting a steady balance between internal forces (e.g., negative buoyancy vs viscous resistance). The arrival of the passive margin perturbs the convergence velocity only slightly, given that the increase in the negative buoyancy provided by the subduction of the dense underplating material is somewhat counterbalanced 

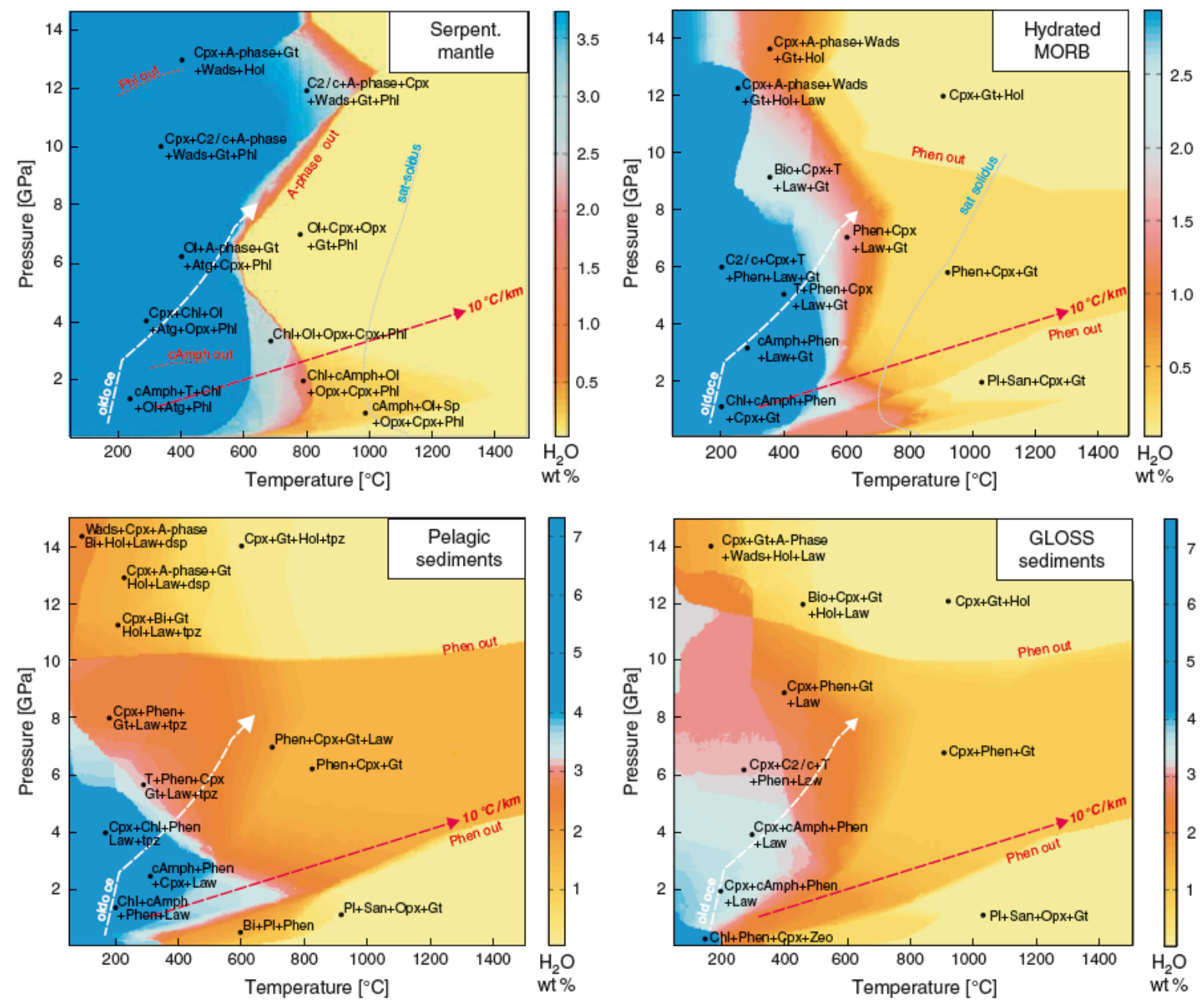

Fig. 3.3 Stable mineral assemblages and bound water content for four relevant rock types as a function of pressure and temperature. These plots were calculated using an augmented/ modified version of the Holland and Powell (1998) thermody

by the low density sediments of the miogeoclinal prism (Fig. 3.1c). We stress here that model velocities are not imposed as boundary conditions, but emerge self-consistently in the simulations as response to internal forces. For the range of values adopted for the rheological parameters (Table 3.4), the velocities in our simulations are comparable to those measured by geodetic surveys (Sella et al. 2002).

The third stage begins with the arrival of the continental crust to the trench (Fig. $3.4 \mathrm{~g} \mathrm{i}$ ). At this point the convergence velocity increases during a short period of time due to a concomitant increase in the total negative buoyancy of the slab. This latter

namic database (see Appendix A.6). Two illustrative geotherms for a "hot" and "cold" slab are shown. Note that the scales saturate at water contents of $4 \%$.

increase is consequence of two main effects: (1) densification of the subducted crust due to changes in the mineral assemblages (i.e., low-pressure to high-pressure facies), and (2) increase in the thermal thickness of the lithospheric mantle (i.e., more cold material being subducted). We note that the first effect is likely overestimated in the present model given the assumptions of complete thermodynamic equilibrium and dry lithologies for the continental crust (see Table 3.1). We return to (1) and (2) in Sects. 3.3 and 3.6.2.

The fourth and final stage in the evolution of the system is a rapid decrease in convergence velocities 


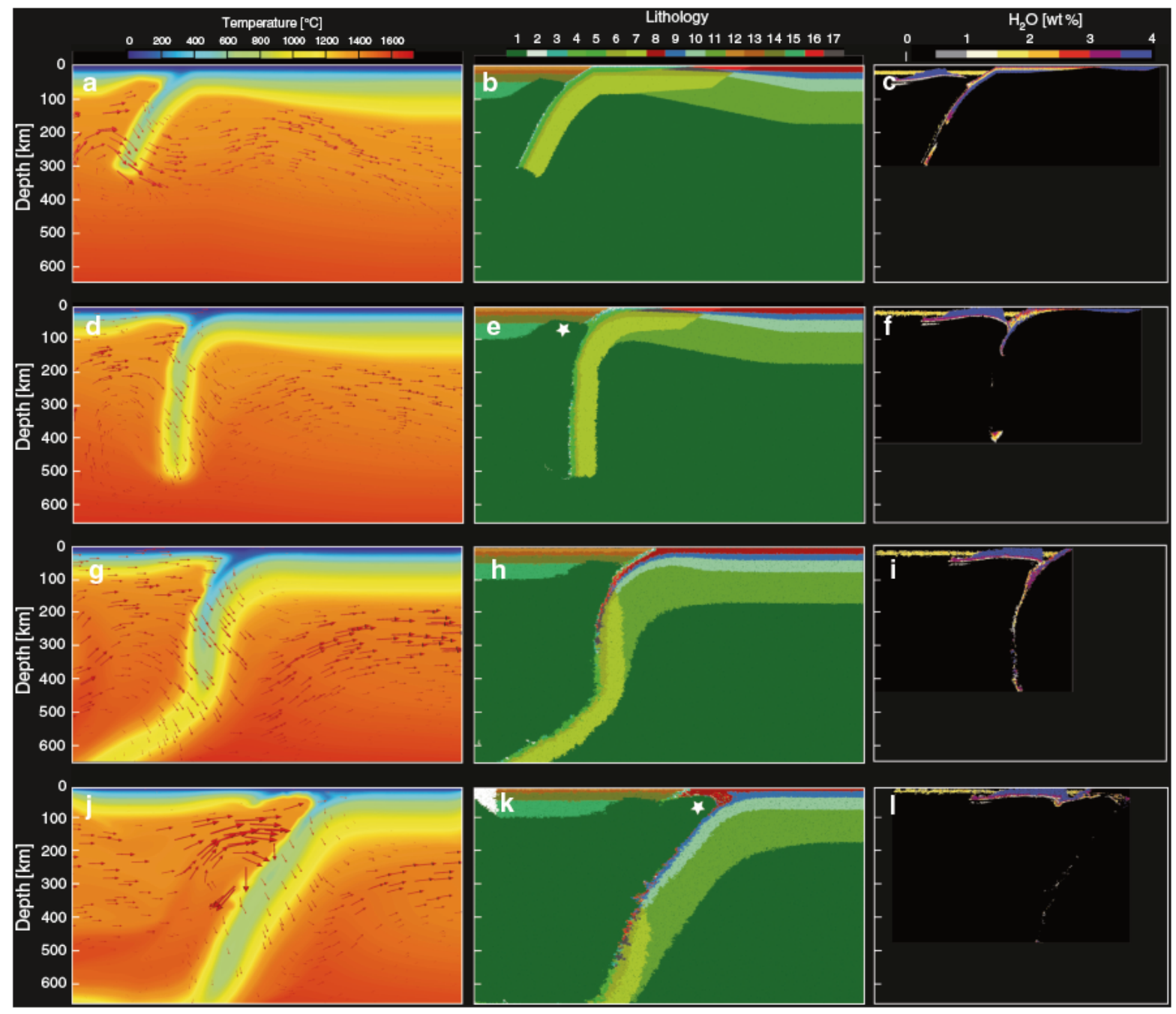

Fig. 3.4 Evolution of the reference model discussed in the text. Left column depicts thermal and velocity structures. Middle column shows the rock types (numbers as in Fig 1c). Right

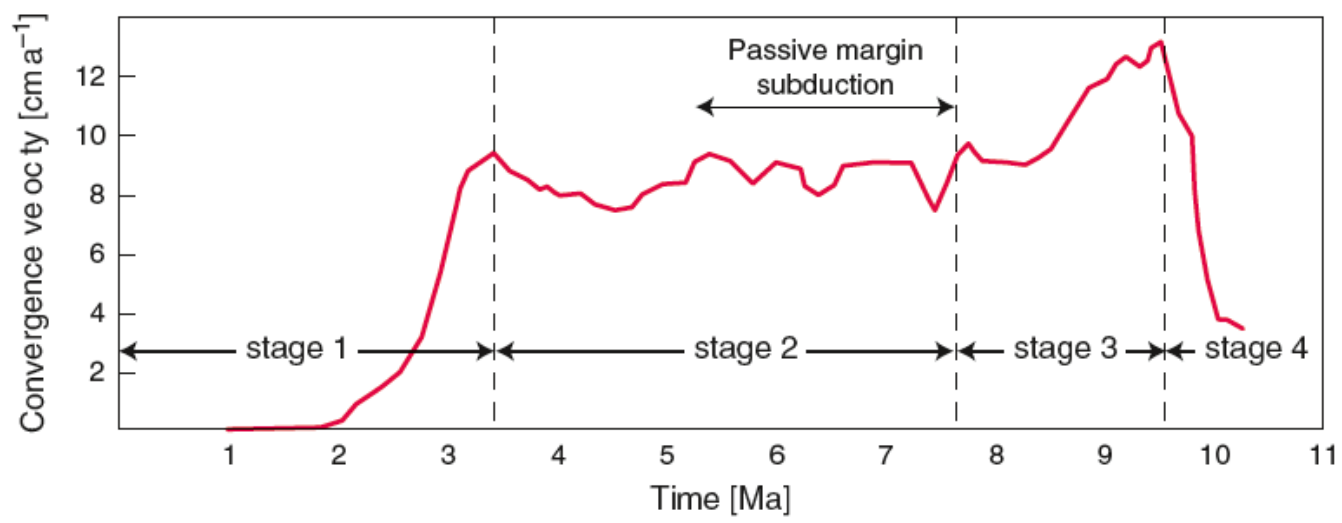

Fig. 3.5 Evolution of convergence velocity predicted by our reference model (Fig. 4). The different stages discussed in the text are shown. 
due to the delamination at lower crustal levels of the continental lithospheric mantle (Figs. 3.4j 1 and 3.5). This stage is similar to the "decoupled collision regime" of Faccenda et al. (2009). As discussed later, the occurrence of such a delamination and its final configuration are largely controlled by the brittle (plastic) rheological model assumed for the crustal components and by the rheological structure of the lithospheric mantle.

A few interesting observations can be made from this simulation. For instance, by looking at the convergence velocity only (Fig. 3.5, from stage 2), one could assign the dramatic slow down from $\sim 9$ to $<4 \mathrm{~cm} \mathrm{a}{ }^{1}$ to an increase in positive buoyancy of the subducting continental plate (note that the increase during stage 3 is relatively small and short-lived and therefore difficult to identify in reconstructions based on geological/ geophysical data). Indeed, a similar evolution of surface velocities (abrupt decrease) has been identified for the Asia-India collision (Guillot et al. 2003) and recently interpreted in terms of the total buoyancy of the Indian plate (Capitanio et al. 2010). Although this scenario is a generally accepted rule of thumb for continental collision, and likely applicable to the Asia-India, our reference model shows another potential scenario. In the simulation, the slow down in the convergence between the colliding plates is not a consequence of a decrease in the total negative buoyancy of the subducting plate, but the result of a mechanical decoupling between the mantle and crust. This decoupling effectively isolates two portions of the originally coherent continental plate, each with different rheological behavior and buoyancy. While the lithospheric mantle (and part of the lower crust) sinks into the convecting mantle due to its large negative buoyancy, the "lighter" crust remains unsubducted with its shallowest parts relatively rigid. Notably, although the continental lithospheric mantle is highly depleted in fusible components (intrinsically buoyant), the thermal structure of the sinking portion makes it more dense than the "fertile" sublithospheric mantle. This will be true as long as the entire sinking volume remains mechanically coherent. Additionally, for similar reasons (i.e., mechanical coherence), the deeper and denser portion of the (oceanic) slab exerts an extra "pull" on the upper continental portion, thus favoring its sinking.

The delamination process described above also causes a lateral shift of the locus of partial melting as well as a change in the amount of melting. Prior to delamination, the locus of partial melting is located below the arc (star in Fig. 3.4e), where the upper plate is thinner. The amount of partial melting in this zone generated in each time step during the retreat of the slab varies between 1 and 5\%. At first, these values seem too low when compared with predictions from kinematic models of subduction, which usually depict values of ca. $1020 \%$ at $2.53 \mathrm{GPa}$ (e.g., Tatsumi and Eggins 1995; Katz et al. 2003). This apparent discrepancy between these two kind of models can be understood as follows. In kinematic models, the slab is forced to subduct with a constant angle and velocity, neglecting the actual balance of internal forces. Such configuration results in a typical corner flow in the mantle wedge, where hot and fertile (i.e., unmelted) material is continuously brought up to shallow depths as consequence of the circulation generated by the imposed velocity on the slab (e.g., Hebert et al. 2009). When this hot material reaches depths of ca. $50 \mathrm{~km}$, it experiences decompression melting and then it is dragged back into deeper levels according to the corner flow circulation. Moreover, most "petrological" models of partial melting in the mantle wedge assume an initial thermal distribution given by a kinematic model (usually a corner flow) and then estimate "instantaneous" melt fractions adopting a batch (equilibrium) model (e.g., Katz et al. 2003). In reality, however, the amount of melting that a mantle parcel can experience is a function of previous events of melt extraction. This is a consequence of the fact that the solidus of a residual peridotite after melt extraction is higher than that of a fertile peridotite (Jordan 1978). In our simulations, the amount of melt generated by a mantle parcel during a time step considers this depletion effect (Appendix A.4) and therefore the material in the mantle wedge is less susceptible to melting, unless it is either hydrated or replaced by fertile mantle. The former occurs at shallow levels below the arc, where temperatures are low enough to allow stabilization of water in the assemblage, and therefore reduce the solidus. The latter is more unlikely in the reference model because of the sub-horizontal flow generated below the arc by the retreating slab (Fig. 3.4). In other words, the typical circulation pattern predicted by a corner flow model does not occur when the slab is in rollback. However, as shown in Sect. 3.5, simulations in which either the arc is fixed or both plates are allow to move freely, exhibit much less trench retreat and a flow pattern in the mantle wedge similar to a corner flow. 
The space created by the delamination of the lithospheric mantle is rapidly filled by rising sublithospheric mantle (Fig. 3.4j 1). This has two major effects in the system: (1) the arc magmatism ceases to exist due to lack of water input from subducted material and the modification of the flow, and (2) the migration of the locus of partial melting, which is displaced towards the forearc following the tip of the delamination (star in Fig. 3.4k). The maximum amount of (dry) melting generated in the mantle in each time step is now $\sim 22.5 \%$. Whether the delamination process stops or continues until all the continental mantle has been recycled into the mantle depends on several factors such as the thermal/ mechanical heterogeneities in the lithosphere, total length of the continent, and the rheological properties of the crust. Parallel simulations in which rheological heterogeneities (i.e., small lateral variations) are included in the lithosphere indicate that the delamination process stops shortly after its initiation (within a few Ma) due to the development of a necking instability and the final breakoff of the slab. Finally, we note that the development of such a delamination seems to be controlled by the fixed continental plate condition (i.e., forced rollback). Models in which the subducting continental plate is allowed to move horizontally (see below) do not promote delamination.

Several features predicted by the reference model resemble geological observations in collisional settings. For instance, the evolution of the surface velocities are compatible with estimations of convergence velocity across the Himalayas, Uralides, and Appalachians (e.g., Dahlen and Suppe 1988; Guillot et al. 2003). The decline of arc volcanism shortly after the arrival of continental crust has also been identified in a number of arc continent collisional settings (e.g., Uralides, Caledonides). On the other hand, the uplift and possible volcanism predicted in the forearc following the initiation of the delamination is more ambiguous. There are no modern equivalents of this stage in an arc continent setting (although a remarkably similar evolution has been proposed for Eastern Anatolia; see Keskin 2007), and it is not clear whether available geological evidence in past arc continent collisions is consistent with this evolutionary model. However, this final stage in our reference model is indeed consistent with geological and geophysical evidence in decoupled orogens in continent continent collisional settings (e.g., Northern Apennines, Carpathians).

\subsubsection{Compositional Effects}

It is now generally accepted that the composition of the continental lithospheric mantle is far from homogenous and that different compositional domains are characterized by different physical responses (e.g., Griffin et al. 2009; Afonso et al. 2010). It is therefore genuine to ask whether such compositional stratifications and lateral variations can influence the dynamics of an arc continent collision. In order to test this we conducted experiments in which the composition of the uppermost lithospheric mantle varies between a highly depleted composition (harzburgitic mantle in Table 3.2) to a slightly depleted one (Tecton mantle in Table 3.2). We stress that these two end-members are based on estimations from a large number of xenoliths recovered in many different continental environments (Griffin et al. 2009) and on integrated petrologicalgeophysical modelling of passive margins (Fernàndez et al. 2010; Fullea et al. 2010).

As shown in Fig. 3.6a, the only noticeable difference between these two models is that the one with a relatively fertile composition tends to generate faster convergence when the continental lithospheric mantle begins to subduct. Although the first order behavior of the system is not affected, the maximum difference in convergence velocities exceeds $\sim 10 \mathrm{~cm} \mathrm{yr}{ }^{1}$, which suggest that compositional heterogeneities in the lithospheric mantle also have the potential to affect the evolution of an arc continent collision. Even more depleted compositions than the one used in our models for the uppermost subcontinental lithospheric mantle have been suggested (Griffin et al. 2009). However, changing the composition from harzburgitic to dunitic in the shallow lithospheric mantle result in a slight decrease of the overall density of the plate, and thus we do not expect to see large differences in the general evolution of our models.

\subsubsection{Lithospheric Structure of the Passive Margin and Continental Plate}

It is expected that the thermal structure of the passive margin and continental lithosphere will influence the dynamics of continental subduction. However, predicting 

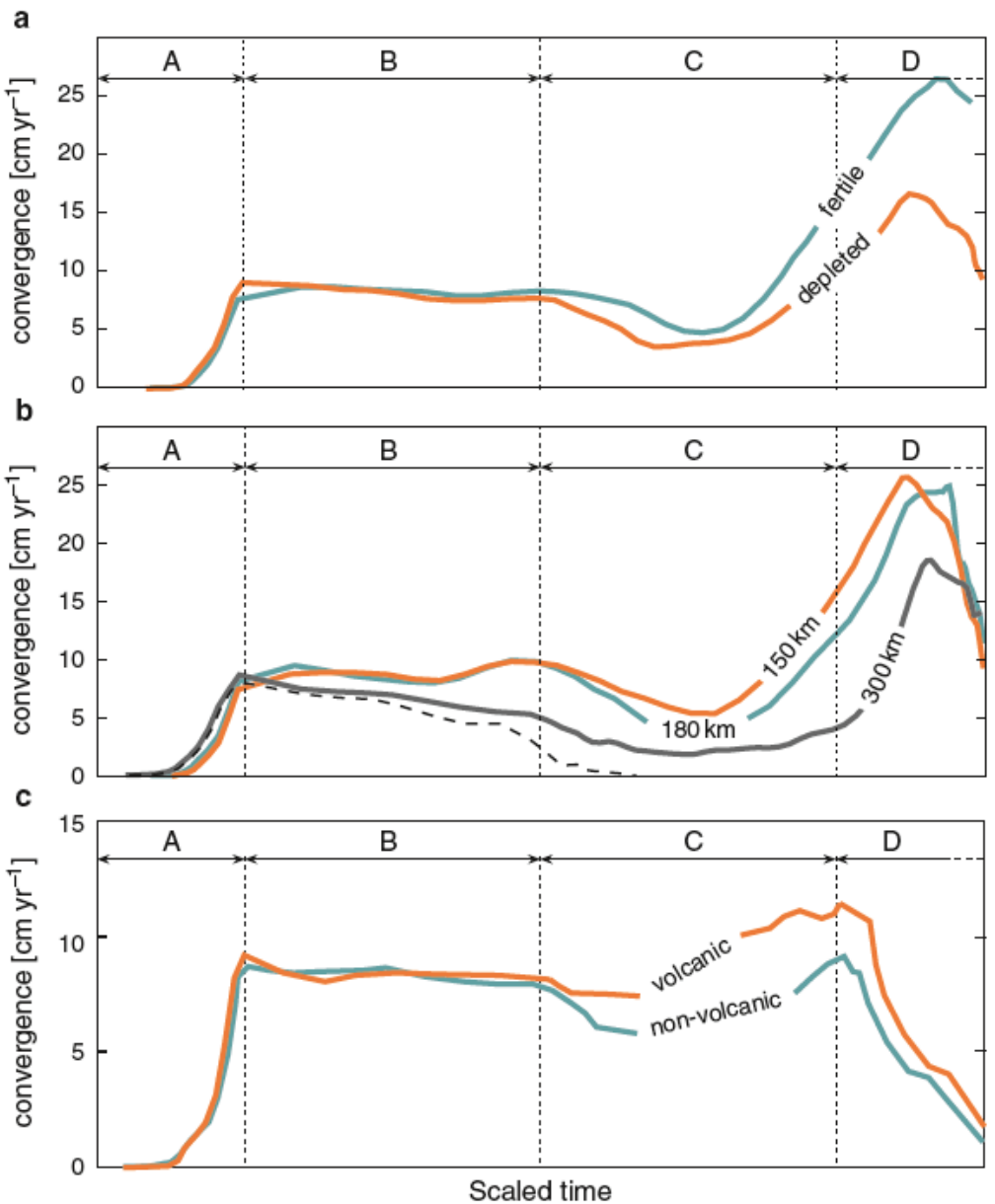

Fig. 3.6 (a) Evolution of convergence velocity for models with depleted vs fertile continental lithospheric mantle. (b) Evolution of convergence velocity for models with different thermal thick nesses in the continental plate. Numbers indicate thermal thick ness in $\mathrm{km}$. The dashed line represents a model with a thickness of $300 \mathrm{~km}$ in which the pre exponetial factor of the lithospheric mantle has been changed from $1.1 \times 10^{5}$ to $1.0 \times 10^{4}$. (c) As in (a) and (b) but for different types of passive margin (see Fig. 7). The curves have been smoothed in comparison with that in Fig. 5.
For the three panels A verticalization of the slab, B subduction of oceanic lithosphere, $\mathrm{C}$ subduction of passive margin, D subduction of continental crust. Note that the absolute time has been scaled in all models to force the curves to fit a unique temporal division of $\mathrm{A}, \mathrm{B}, \mathrm{C}$, and D stages and that all models include "soft" rheologies for the passive margin and continental crust and a fixed far end condition (i.e. zero hori zontal velocity in the far end of the continental plate).

simulations in which the thermal thickness of the continental plate varies from 150 to $300 \mathrm{~km}$. Since the lateral extent of the passive margin remains the same in all three models, the thermal structure of the mantle part of the passive margin also changes accordingly (i.e., the thicker the plate the thicker the passive margin). Figure $3.6 \mathrm{~b}$ shows the convergence velocities predicted by the three models. These results indicate that the long-term effect of increasing the thermal thickness of the subducting plate is to slow down 
subduction. In other words, the "stiffening" effect is more important than the increase in negative buoyancy. Indeed, a parallel simulation with a thermal thickness of $300 \mathrm{~km}$ (dashed black line in Fig. 3.6b) in which the viscosity of the lithospheric mantle was slightly increased within uncertainty limits resulted in total subduction stall and slab breakoff (Sect. 3.7).

\subsubsection{Volcanic Versus Non-volcanic Passive Margins}

The nature of the volcanic margin (i.e., volcanic vs non-volcanic) is likely to affect collision dynamics due to their different geometries and compositions. Briefly, a typical volcanic margin is narrower than a non-volcanic one, and includes a relatively thick "magma crust" composed of heavily intruded continental crust plus underplated mafic to ultra-mafic material (the so-called high-velocity bodies, Geoffroy 2005). The reference model described above is based on the structure of the Namibian volcanic margin, and thus we assume this model to represent a typical volcanic margin. For the non-volcanic case, we modified the passive margin structure of the reference model to accommodate a thinner crust of less mafic composition (Fig. 3.7). Note that the rheology of this new body changes accordingly to be consistent with the new composition (see Tables 3.4 and 3.5).

The resulting convergence velocities from two simulations that differ only in the geometry and composition of the passive margin are shown in Fig. 3.6c. To the firstorder, the evolution of both models are similar, and they only differ in the absolute value of their convergence velocity. The volcanic passive margin becomes slightly faster once the passive margin begins to subduct, and remains faster for as long as the slab remains mechanically coherent. The maximum absolute difference in velocity occurs during the subduction of the passive margin and reaches a peak value of $\sim 2.5 \mathrm{~cm}$ yr ${ }^{1}$, although for most of the simulation is $2 \mathrm{~cm} \mathrm{yr}{ }^{1}$.

\subsubsection{Models with Free Plates}

We carried out experiments in which both plates were allowed to move freely in response to the large-scale circulation. In this case, the continental plate is $1,000 \mathrm{~km}$ long (i.e., $500 \mathrm{~km}$ longer than in the reference model) and the numerical box was extended to a total of $3,000 \mathrm{~km}$. This models could be representative of a scenario in which the continental plate is bounded in the far end by a mid-ocean ridge. Two snapshots of the thermal and velocity fields for the same model are shown in Fig. 3.8, from which it is evident that the dynamics of the system is considerably different from those in which the continental plate is fixed at the far end (Fig. 3.4). The convergence velocity in this case is dominated by the motion of the subducting plate rather than the arc. This indicates that when both plates are free to move (i.e., both having a mid-ocean ridge as the

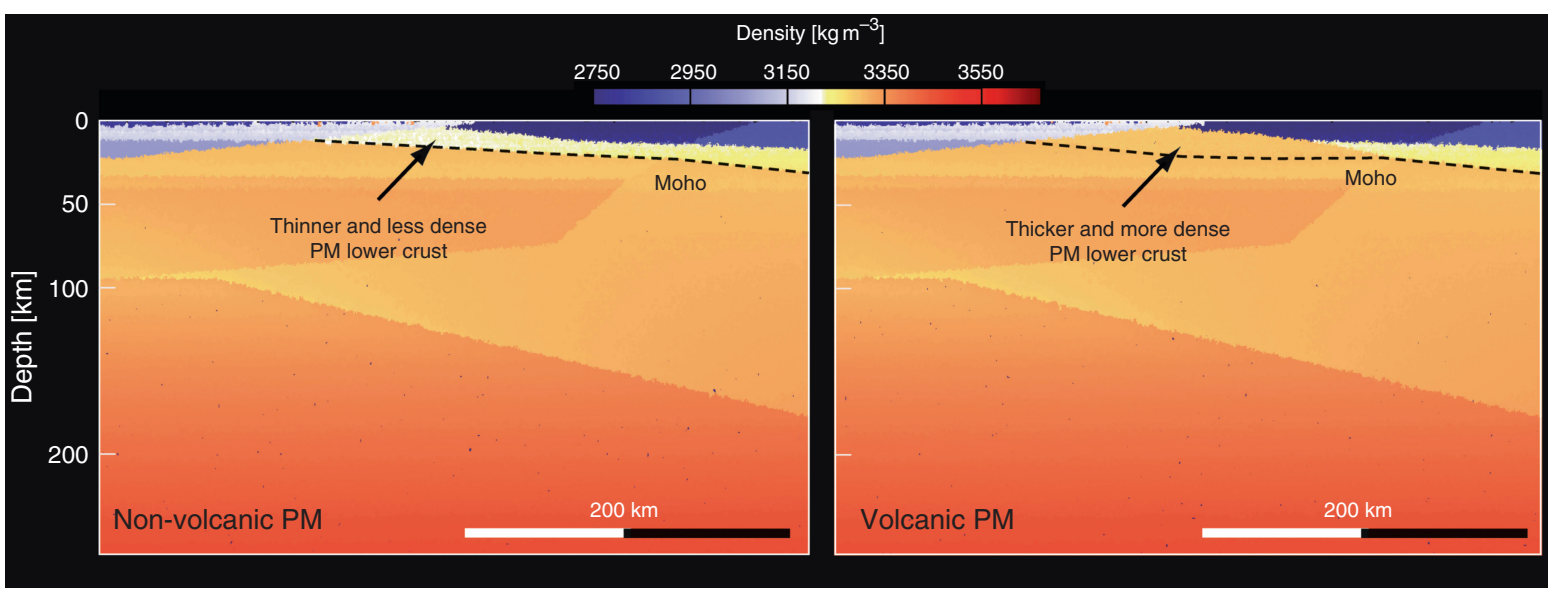

Fig. 3.7 Initial density structures for two different models of passive margins tested in this study. See text for details. 


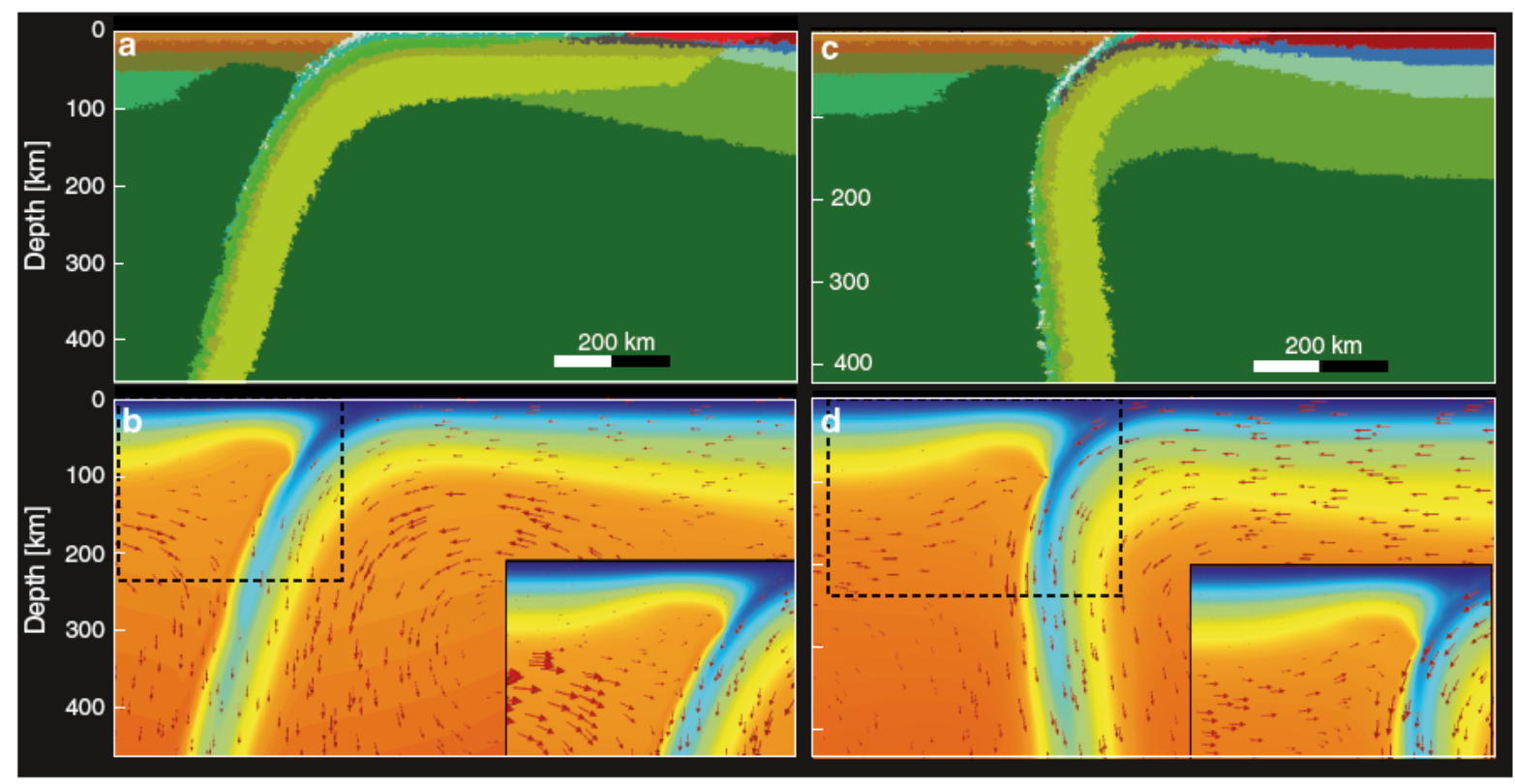

Fig. 3.8 Two snapshots at different times from a simulation with both plates free. The dashed boxes in $b$ and $d$ refer to the zoom in the lower corner. Scales are as in Fig. 1a and c.

far end boundary), it is easier for the system to "slide" the long continental plate over the low viscosity asthenosphere than produce a slab rollback. The latter involves the widespread deformation (motion) of large volumes of deep and viscous sublithospheric material, which is inefficient in terms of dissipation of available potential energy. Contrarily, when the horizontal component of the velocity in the continental plate is towards the trench, deformation is localized only along narrow areas adjacent to the slab and in the low viscosity asthenosphere (Fig. 3.8b, d). This scenario is favored by the strong non-linear dependence of viscosity on strain rate (Appendix A.3) and represents a more efficient mechanism of energy dissipation. Note that although the continental plate moves towards the trench, the global flow results in a slow trench retreat.

A consequence of this type of motion is that the mantle wedge beneath the arc experiences a circulation pattern more similar to a typical corner flow (zooms in Fig. 3.8b, c). As previously mentioned, this type of circulation favors a continuous replenishment of hot fertile mantle into the mantle wedge, which in turn favors larger degrees of melting. However, although the actual large scale flow is substantially different from the one produced by slab rollback, we see no significant difference in the general pattern and absolute values of convergence velocities between the two cases. Also, the delamination at lower crustal levels described above do not occur in models with free plates, which end in either a slab breakoff or in the subduction of large section of continental lithosphere, depending on the rheological parameters assumed in the simulations (see next section).

\subsubsection{Rheological Effects: The Ghost in the Machine}

Capturing in a numerical model the whole range of possible rheological behaviors observed in both laboratory experiments and natural rock samples is a difficult task, partly because of the physical nature of the deformation mechanisms, but also due to the large experimental uncertainties in rheological parameters. The outcomes of any thermomechanical simulation are strongly dependent on the rheological parameters assumed for the materials, particularly when nonlinear (i.e., non-Newtonian) constitutive relations are employed. In this section we briefly explore the influence that these assumed rheological properties 
have on our simulations, as well as the implications for interpreting processes associated to collisional settings. A thorough and systematic analysis of these effects will be presented elsewhere (Zlotnik and Afonso, in preparation).

\subsubsection{Detachment of the Oceanic Crust}

It has long been suggested that the contrast in density and rheological behavior between the subducted oceanic crust and the underlying serpentinized mantle could result in a separation (decoupling) of the eclogitized oceanic crust from the rest of the slab (e.g., Ringwood 1982; van Keken et al. 1996, and references therein). Whether this process occurs in reality has important implications for the interpretation of geochemical and seismological data (van Keken et al. 1996; Lee and Chen 2007, and references therein). In our simulations, different modes of spontaneous separation of either the entire oceanic crust or part of it occur depending on the rheological stratification assumed for the oceanic domain. We observe large portions of oceanic crust detaching from the rest of the slab only for extremely low critical yield stresses $\left(\tau_{c} \lesssim 100 \mathrm{MPa}\right)$ in the lower oceanic crust and serpentinized mantle (Fig. 3.9a). When yield stresses in better agreement with experimental results are used (e.g., Shimada 1993; Renshaw and Schulson 2004), the volume of detached oceanic crust decrease, but do not cease to occur in our models (Fig. 3.9d). These detachments occur in response to the difference in buoyancy and rheology between the eclogitized crust and the surrounding mantle bodies (Fig. 3.9b, e).

An interesting consequence of separating the oceanic crust from the slab is related to the significant change in negative buoyancy that the slab experiences, even when the volume of detached crust is not large. As seen in Fig. 3.9b, e, the oceanic crust is the denser part of the slab at all depths down to the top of the lower mantle and it contributes approximately between 12 and $16 \%$ to the total negative buoyancy of the slab (depending on the slab's total length). Indeed, our simulations (Fig. 3.9c, f) show a sudden decrease in convergence velocity whenever a portion of the oceanic crust is separated from the rest of the slab. Although whether these detachments get trapped at the bottom of the transition zone or sink into the lower mantle is beyond the scope of this chapter, we note that it mainly depends on the large scale flow, the viscosity contrast assumed between the upper and lower mantle, and the temperature difference between the detachments and the surrounding mantle.

\subsubsection{The Rheology of the Continental Crust}

There is no doubt that the rheology of continental crustal units plays a major role in the dynamics of the collision (e.g., Toussaint et al. 2005; Burov and Yamato 2008; Warren et al. 2008). However, the choice of representative creep laws for the different units making up the continental crust is not always straightforward. The viscous behavior of the continental upper crust has been traditionally modelled using the creep law of a "wet quartzite" (e.g., Ranalli 1995; Afonso and Ranalli 2004; Nikolaeva et al. 2008; Faccenda et al. 2009), although arbitrarily stronger creep laws have been also used (e.g., Li and Gerya 2009). On the other hand, there is much less agreement as to what creep law should be adopted for the continental lower crust. In lack of more reliable data, several choices are usually tested in the literature, ranging from relatively soft "felsic granulite" laws to much stronger "dry mafic diabase" laws (cf. Afonso and Ranalli 2004). Arguably, the modelling of the brittle behavior of rocks is even more problematic. Although most authors adopt a plastic criterion to model brittle failure, the assumed criterion varies considerably amongst different authors. In this paper we use a modified version of the von Mises criterion that accounts for material strengthening with pressure (see Appendix A.3). In contrast to most previous studies, we use a constant maximum yield stress to account for the experimentally observed phenomenon of "high-pressure failure" (e.g., Shimada 1993; Renshaw and Schulson 2004; Zang et al. 2007). We vary this yield stress between 300 and $350 \mathrm{MPa}$ in agreement with experimental and theoretical estimations.

We carried out a number of simulations in which we set "soft" and "strong" rheologies to the entire crust, as well as mixed cases (e.g., strong UC and soft LC, see Tables 3.3 3.5). We find that models with a soft upper crust are characterized by two main mechanical features. Firstly, the upper crust remains mechanically decoupled from the lower crust at most conditions, even at very low strain rates $\left(\lesssim 1 \times 10^{17} \mathrm{~s}^{1}\right)$. Secondly, the upper crust yields viscously and/or 

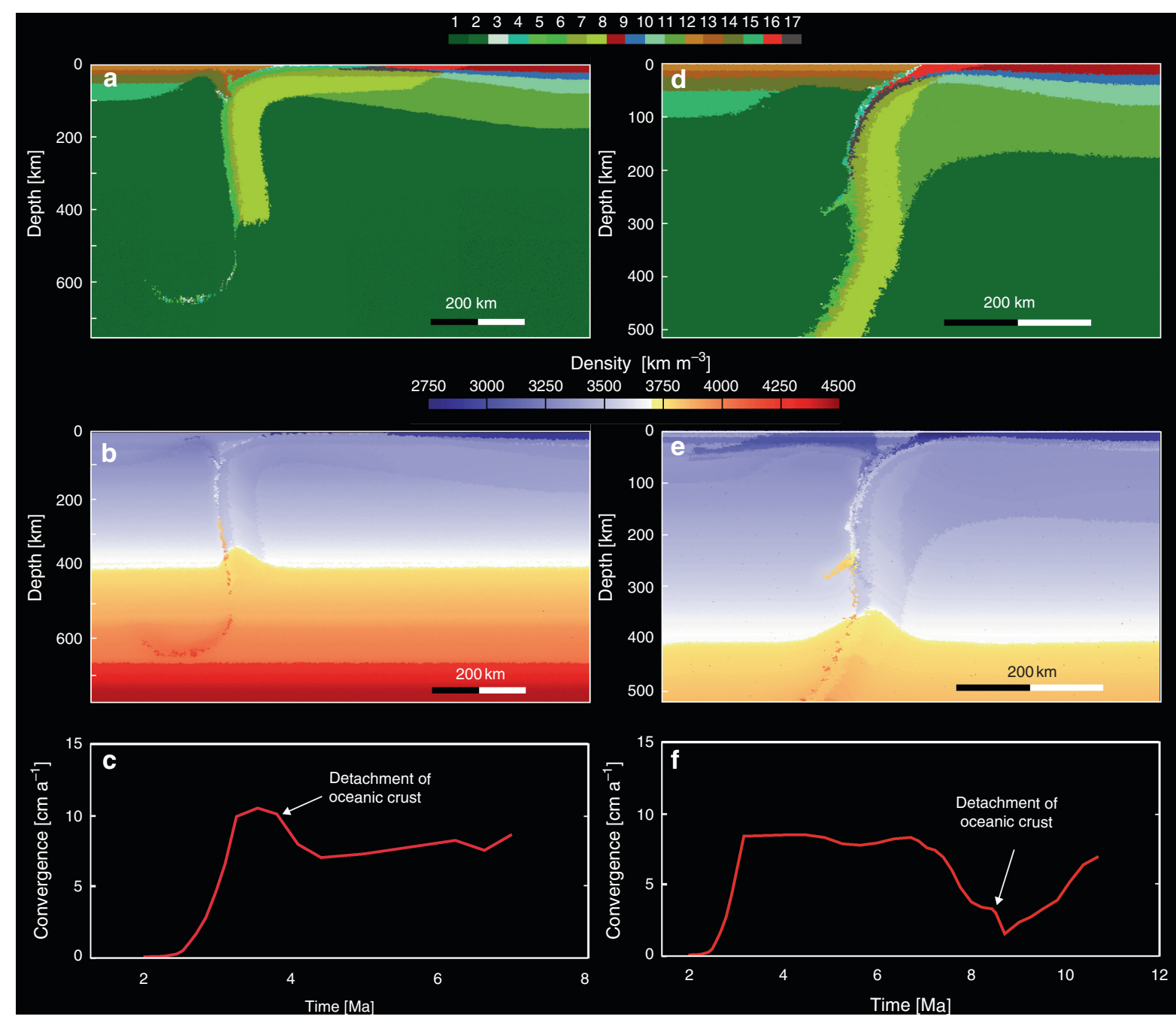

Fig. 3.9 Two different detachments of oceanic crust from the slab. In the left column the yield stress of the oceanic lower crust and serpentinized mantle (4 and 5) is $60 \mathrm{MPa}$. In the right column the yield stress of the oceanic lower crust

plastically under relatively low stress levels, facilitating widespread deformation instead of localized concentration of strains. These two factors, and the fact that the upper crust is intrinsically less dense than the other lithologies involved in the collision, favor crustal thickening rather than subduction of the upper crust. When this is the case, subduction of significant volumes of upper continental down to depths $>100140 \mathrm{~km}$ crust is difficult to achieve in our simulations (Fig. 3.10). We observe that after an episode of accumulation of upper crust material and forced subduction to depths of $\sim 100 \mathrm{~km}$, a second episode of rapid

and serpentinized mantle is $300 \mathrm{MPa}$ (Table 4). Bottom panels (c and $\mathrm{f}$ ) show the evolution of the convergence velocity for these two models.

(pulse-like) exhumation occurs in response to the build up of a critical volume of positively buoyant material (sediments + upper crust). This reinforces observations from recent works (Sobolev and Babeyko 2005; Gerya et al. 2006; Warren et al. 2008; Yamato et al. 2008; Beaumont et al. 2009; Li and Gerya 2009) in which pulse-like exhumation episodes from depths of about $100160 \mathrm{~km}$ have been found to be not only possible but an integral part of orogenic cycles. However, exhumation from depths $>200 \mathrm{~km}$, as suggested by mineralogical evidence (e.g., Haggerty and Sautter 1990; Ye et al. 2000; Green et al. 2000; Song et al. 
Table 3.3 Creep parameters

\begin{tabular}{|c|c|c|c|c|c|}
\hline Lithology & $A$ & $n$ & $E$ & $V$ & Model bodies \\
\hline Quartzite (wet) ${ }^{\mathrm{a}}$ & $3.2 \times 10^{-4}$ & 2.3 & 154 & 0 & $\overline{c o n t U C}$, arcUC, oceSed, pmSed \\
\hline Quartzite (hard) ${ }^{\mathrm{a}}$ & $3.2 \times 10^{-7}$ & 2.3 & 154 & 0 & contUC \\
\hline "Undried" diabase (wet) ${ }^{\mathrm{b}}$ & $2.0 \times 10^{-4}$ & 3.4 & 260 & 0 & oce $L C, \operatorname{arc} L C$ \\
\hline Mafic granulite ${ }^{c}$ & $1.4 \times 10^{4}$ & 4.2 & 445 & 0 & $\operatorname{cont} L C$ \\
\hline Diabase $^{c}$ & $1.0 \times 10^{2}$ & 3.4 & 260 & 0 & oceUC \\
\hline${\text { Maryland diabase }(\text { dry })^{\mathrm{d}}}$ & 8.0 & 4.7 & 485 & 0 & under \\
\hline Diff. creep peridotite (wet) ${ }^{\mathrm{e}}$ & $1.0 \times 10^{6}$ & 1.0 & 350 & 4 & mantle \\
\hline Disl. creep peridotite (wet) ${ }^{\mathrm{e}}$ & $9.0 \times 10^{1}$ & 3.5 & 520 & 11 & mantle \\
\hline Diff. creep peridotite $(\text { dry })^{\mathrm{e}}$ & $1.5 \times 10^{9}$ & 1.0 & 375 & 4 & mantle \\
\hline Disl. creep peridotite (dry) ${ }^{\mathrm{e}}$ & $1.1 \times 10^{5}$ & 3.5 & 530 & 14 & mantle \\
\hline
\end{tabular}

Units: pre exponential parameter, $A$, in $\mathrm{Mpa}^{-n} s^{-1}$; Activation energy, $E$, in $\mathrm{kJ} \mathrm{mol}^{-1}$; Activation volume, $V$, in $\mathrm{J} \mathrm{mol}^{-1} \mathrm{Mpa}^{-1}$. Activation volume is taken 0 if no conclusive experimental results are available

Model bodies abbreviations: cont continent, arc arc, oce ocean, UC upper crust, LC lower crust, under underplating

References: ${ }^{a}$ Kirby and Kronenberg 1987, ${ }^{\text {b }}$ Shelton and Tullis 1981, ${ }^{\mathrm{c}}$ Kirby 1983, ${ }^{\mathrm{d}}$ Mackwell et al. 1998, ${ }^{\mathrm{e}}$ Hirth and Kohlstedt 2003

Table 3.4 Setup of the reference model

\begin{tabular}{|c|c|c|c|c|c|c|}
\hline & & & Creep parameters & Plastic params $\left(\mu / c_{0} / \max \right)$ & Composition & $\operatorname{RHP}\left(\mu \mathrm{W} \mathrm{m}^{-3}\right)$ \\
\hline \multirow[t]{4}{*}{ Continent } & \multirow[t]{2}{*}{ Crust } & Upper & Wet quartzite & $0.6 / 100 / 300$ & cont. UC & 1.2 \\
\hline & & Lower & Mafic granulite & $0.6 / 100 / 300$ & cont. LC & 0.4 \\
\hline & \multirow[t]{2}{*}{ Mantle } & Upper & Dry peridotite & & cont. UM & 0.0 \\
\hline & & Upper & Wet peridotite & & Tecton & 0.0 \\
\hline \multirow[t]{5}{*}{ Ocean } & \multirow[t]{3}{*}{ Crust } & Sedim. & Wet quartzite & $0.4 / 0 / 300$ & Pelag. Sedim. & 0.9 \\
\hline & & Upper & Diabase & $0.4 / 0 / 300$ & oce. UC & 0.4 \\
\hline & & Lower & Maryland diabase & $0.4 / 0 / 300$ & oce. LC & 0.4 \\
\hline & \multirow[t]{2}{*}{ Mantle } & Upper & Dry peridotite & & Harzburg. & 0.0 \\
\hline & & Upper & Wet peridotite & & Tecton & 0.0 \\
\hline \multirow[t]{4}{*}{ Arc } & \multirow[t]{2}{*}{ Crust } & Upper & Wet quartzite & $0.4 / 0 / 300$ & oce. UC & 0.2 \\
\hline & & Lower & Maryland diabase & $0.4 / 0 / 300$ & oce. LC & 0.0 \\
\hline & \multirow[t]{2}{*}{ Mantle } & Upper & Dry peridotite & & Harzburg. & 0.0 \\
\hline & & Upper & Wet peridotite & & Tecton & 0.0 \\
\hline \multirow[t]{4}{*}{ Passive margin } & \multirow[t]{2}{*}{ Volcanic } & Sedim. & Wet quartzite & $0.4 / 0 / 300$ & Prism sed. & 0.8 \\
\hline & & Under & Maryland diabase & $0.4 / 0 / 300$ & Under. & 0.0 \\
\hline & \multirow[t]{2}{*}{ Non volcanic } & Sedim. & Dry peridotite & $0.4 / 0 / 300$ & Prism sed. & 0.8 \\
\hline & & Under & Wet peridotite & $0.4 / 0 / 300$ & cont. LC & 0.0 \\
\hline Sub lith & Mantle & & Wet peridotite & & Sublith. mantle & \\
\hline
\end{tabular}

2004; Liu et al. 2007; Scambelluri et al. 2008), has not been observed in these studies.

Models with a stronger upper continental crust are more strongly coupled to the lower crust and show less accumulation and larger subducted volumes of upper crust material before the systems stalls (Fig. 3.10). Although the density of the upper continental crust remains lower than the surrounding mantle down to depths of $\sim 250300 \mathrm{~km}$, its higher intrinsic viscosity and low temperatures keep it mechanically coupled to the rest of the slab, allowing a more continuous subduction of this unit. However, should separation from the lower crust occur by any means at depths $<250300 \mathrm{~km}$, small pieces of upper crust could potentially return to shallower depths by their own buoyancy and get entrained within the units comprising the orogen. We have not observed this in our simulations, but its importance to reconcile mineralogical observations with numerical simulations warrants more work towards this end. Below these depths, however, our simulations predict a sudden increase in the density of subducted continental material due to the appearance of stishovite, CAS, and K-hollandite in the assemblage (see Fig. 3.11), and the increase of modal 
Table 3.5 Selected representative experiments discussed in the text

\begin{tabular}{|c|c|c|c|c|c|c|c|c|c|c|}
\hline \multirow[t]{2}{*}{ Model } & \multicolumn{2}{|l|}{ Continent } & \multirow{2}{*}{$\begin{array}{l}\text { P. margin } \\
\text { structure }\end{array}$} & \multicolumn{2}{|c|}{ Cont. rheology } & \multicolumn{2}{|c|}{ P.M. rheology } & \multicolumn{2}{|c|}{ Oce. rheology } & \multirow{2}{*}{$\begin{array}{l}\text { Boundary } \\
\text { conditions }\end{array}$} \\
\hline & Thickness & Mantle comp. & & Creep & Plastic & Creep & Plastic & Creep & $\overline{\text { Plastic }}$ & \\
\hline 0024 & 180 & Depleted & Volcanic & & & & & & Soft $^{\mathrm{a}}$ & Fixed cont. \\
\hline 0093 & 180 & Fertile & Non volcanic & & & & & & & Fixed cont. \\
\hline 0096 & 150 & Depleted & Volcanic & & & & & & & Fixed cont. \\
\hline 0098 & 300 & Depleted & Volcanic & & & & & & & Fixed cont. \\
\hline 0100 & 180 & Depleted & Volcanic & & & & Strong $^{\mathrm{b}}$ & & & Fixed cont. \\
\hline 0102 & 180 & Depleted & Non volcanic & & & & Strong $^{\mathrm{b}}$ & & & Fixed cont. \\
\hline 0109 & 180 & Depleted & Volcanic & Strong ${ }^{\mathrm{c}, \mathrm{d}}$ & & & & & & Fixed cont. \\
\hline 0110 & 180 & Depleted & Volcanic & Strong $^{c}$ & & & Strong $^{\mathrm{b}}$ & & & Fixed cont. \\
\hline 0111 & 180 & Depleted & Volcanic & Strong $^{c}$ & & & & & & Fixed cont. \\
\hline 0122 & 180 & Depleted & Non volcanic & & & & & & & Fixed cont. \\
\hline 0123 & 180 & Depleted & Volcanic & & & & & & & Fixed cont. \\
\hline 0124 & 180 & Depleted & Volcanic & & Strong $^{\mathrm{e}}$ & & Strong $^{\mathrm{f}}$ & & & Fixed cont. \\
\hline 0126 & 180 & Depleted & Volcanic & & & & & & & Free plates \\
\hline 0202 & 180 & Depleted & Volcanic & Strong $^{\mathrm{d}}$ & & & & & & Fixed cont. \\
\hline
\end{tabular}

${ }^{\mathrm{a}} 0 / 0 / 50 \mathrm{MPa}$

${ }^{\mathrm{b}} 0 / 0 / 250 \mathrm{MPa}$

${ }^{\mathrm{c}}$ Upper crust: Quartzite (hard)

${ }^{\mathrm{d}}$ Lower crust: Maryland Diabase

e $0.6 / 100 \mathrm{MPa} / 350 \mathrm{MPa}$

f $0.6 / 100 \mathrm{MPa} / 250 \mathrm{MPa}$

garnet. This new assemblage remains denser than the surrounding mantle down to the bottom of the transition zone ( 660 km depth), where the ambient mantle rich in Mg-perovskite becomes denser. These predictions are in good agreement with estimations from high-T-P experiments on natural and synthetic samples with compositions representative of continental material (see Appendix A.6). It is therefore difficult to imagine a mechanism that could exhume significant volumes of subducted continental material once it has reached $250300 \mathrm{~km}$ depth, although geochemical signatures could be "picked up" by ascending plumes (Hart et al. 1992; Workman et al. 2004). We thus conclude that this depth range effectively mark the "point of no return" for subducted continental material, in agreement with previous estimations from laboratory experiments (e.g., Irifune et al. 1994; Dobrzhinetskaya and Green 2007).

Note that regardless of the average rheology assumed for the continental crust or the final configuration (delamination vs slab breakoff), its lower section is prone to deep subduction and recycling for all tested conditions (Figs. 3.1, 3.4, 3.10, 3.12). The main reason for this is its high intrinsic density (e.g., Fig. 3.10), which in turn results from the dry mafic composition assumed. Although this mafic composition is based on best available estimates from outcrops, geophysical evidence, and xenoliths (Rudnick and Gao 2003), it is likely that more felsic components exist in the lower crust in some continental areas. This could somewhat restrict the amount of continental crust that can be subducted during the collision. Perhaps more important is the dry assumption. There is abundant evidence that the continental lower crust contains bound water, although the actual amount is difficult to constrain and could vary significantly across different tectonic settings (cf. Ague 2003; Rudnick and Gao 2003). Allowing for initial water contents of $\gtrsim 1 \%$ in the lower crust decreases its average density (at crustal conditions) by $\sim 3 \%$ due to the presence of hydrous phases (e.g., amphiboles, micas, etc.) and increases the pressure $(\sim 0.5 \mathrm{GPa})$ at which a low-T eclogitic assemblage (breakdown of plagioclase) first appears. It follows from the above arguments that the amount of subducted continental lower crust estimated from our simulations should represent an upper limit.

\subsubsection{The Aftermath: Slab Breakoff}

Although the original model of slab breakoff (Davis and Blanckenburg 1995) was proposed to explain a number of common observations in continent 


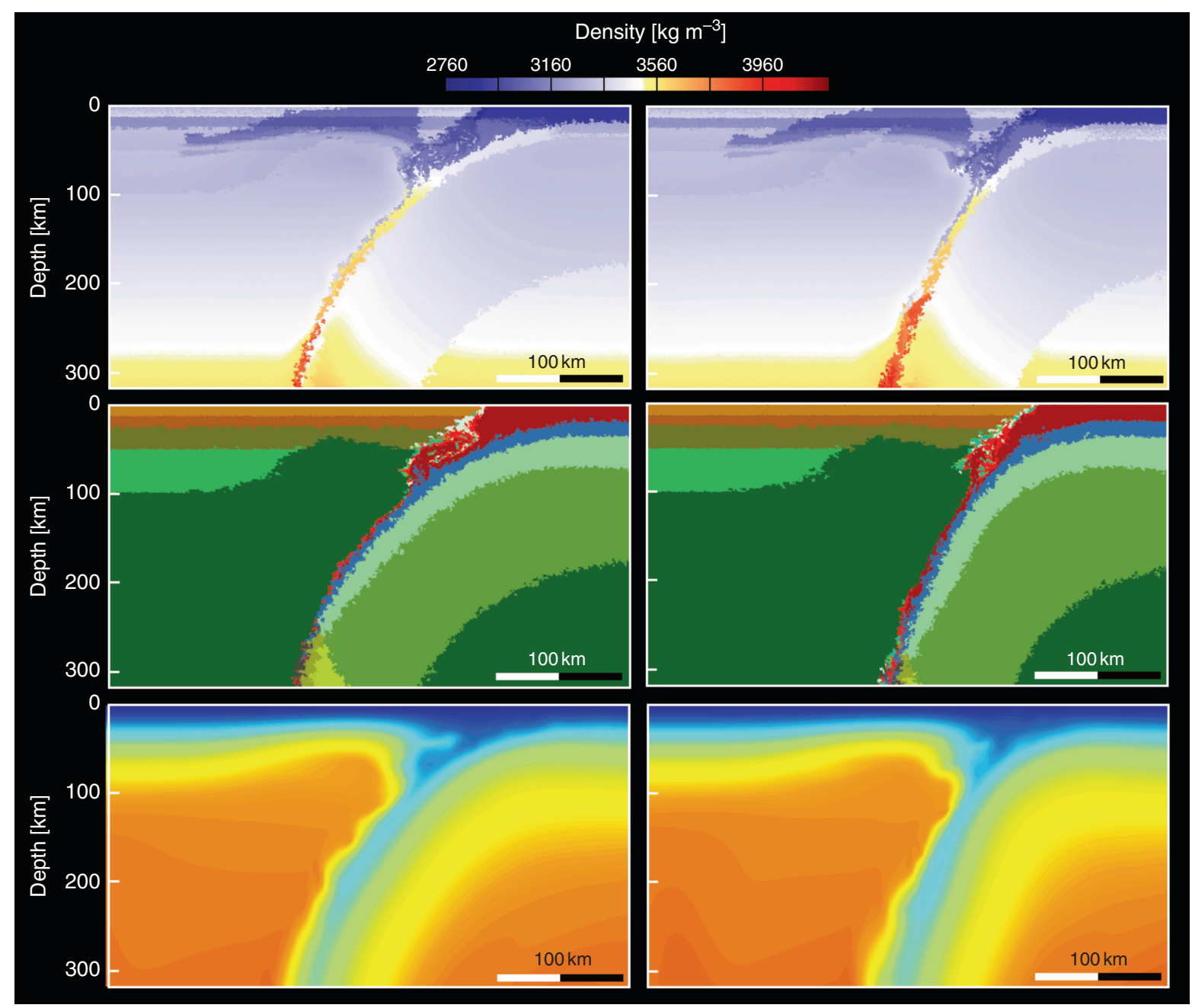

Fig. 3.10 Two snapshots of two different simulations in which the rheological parameters for the continental crust are different. Left column represents the case of a "soft" continental crust, whereas the right column includes a "strong" continental crust.

continent collision environments such as anomalous rates of uplift, metamorphic facies, post-orogenic bimodal magmatism, and P-T paths of exhumed rocks (cf. Davis and Blanckenburg 1995, 1998), it has been also suggested to be an integral part of arc continent collisions (e.g., Dewey 2005). In our models, the necessary condition for the development of slab breakoff is that displacement along the main fault (i.e., subduction fault) decrease to values $<0.8 \mathrm{~cm} \mathrm{yr}{ }^{1}$. With such low values, the main fault can be considered effectively locked. As a result, the large negative buoyancy of the slab generates a significant state of tension along its entire length, which eventually get localized in
Upper panels show density structure; middle panels show rock type; lower panels depict temperature field (scales as in Fig. 1a and c). See Tables 15 for the actual rheological parameters.

regions where the slab is weakest. In our simulations this region is consistently located on the continental side of the slab (Fig. 3.12), where the high strain rates created in response to the bending of the lithosphere generate a pronounced low in the effective viscosity. No simulation in which the passive margin is subducted predicted either symmetrical necking or strain localization in the arc side. The latter does not take place due to two main factors: (1) at the time of fault locking, the arc side of the fault has been significantly cooled by thermal diffusion due to the adjacent subduction of cool material and therefore its viscosity is 


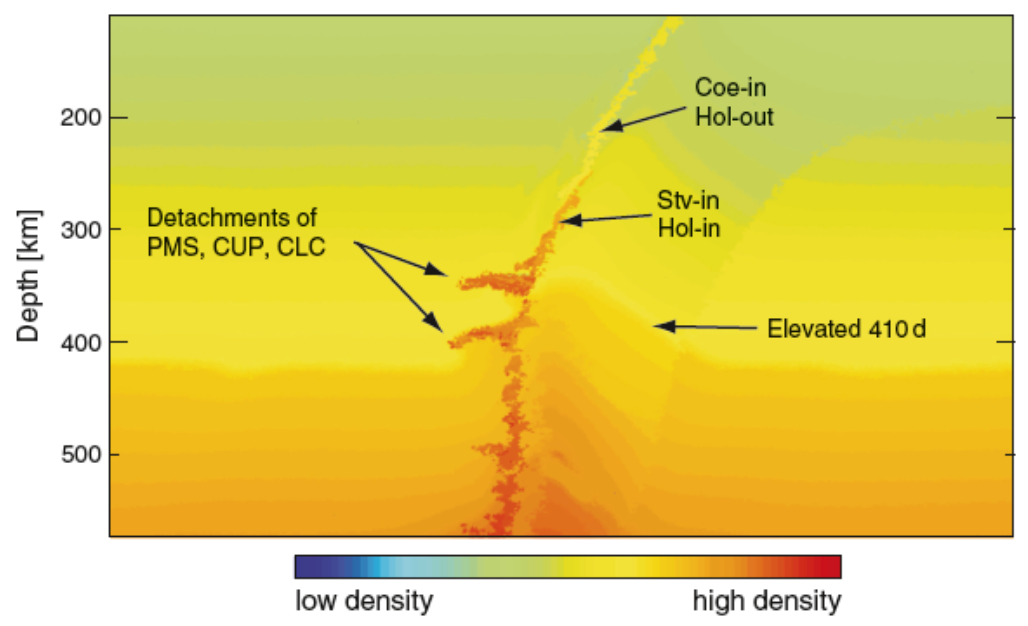

Fig. 3.11 Density structure of subducted continental material in a model with strong continental crust. Note the large jump in density due to the appearance of high density phases stishovite and $\mathrm{K}$ hollandite in the assemblages. PMS passive margin sediments, CUP continental upper crust, CLC continental

relatively high; (2) there is no significant bending in the arc to produce high strain rates and thus low viscosity.

In contrast, models with unrealistically strong rheologies in the passive margin tend to stop subduction before significant portions of the passive margin can subduct. In this case, slab breakoff results from symmetrical necking at deeper levels, entirely within oceanic lithosphere (Fig. 3.13). This general pattern of symmetrical necking at deeper levels compares with the results obtained by Gerya et al. (2004) for intraoceanic subduction zones. However, geological evidence for partial if not total subduction of the passive margin (e.g., Urals, Caledonides) suggest that this model of slab breakoff is not entirely representative of arc continent collisional settings.

The evolution of the slab breakoff (and all the processes associated with it) depicted in Fig. 3.12 is rapid, taking $<2$ Ma to completely detach the slab after fault locking. This timescale agrees well with estimations in real arc-collisional settings (e.g., Dewey 2005). A short episode of hydrous melting $(\$ 1 \%)$ in the lithospheric mantle associated with mantle upwelling below the forearc is also observed. Although we do not model melting of crustal units, we expect a concomitant melting episode in adjacent parts of the crust. A similar short-lasted and volumetrically small episode of partial melting occurs below the arc once the slab is completely detached and sublithospheric mantle flow

lower crust. The detachments tend to nucleate near the transition between "low density" and "high density" assemblages in response to the difference in buoyancy between the latter and the surrounding mantle.

becomes continuous between the remaining lithosphere and the sinking slab (Fig. 3.12f). Mantle melting in the forearc thus precedes melting below the arc by $\sim 0.81 .0 \mathrm{Ma}$.

Another consequence on the breakoff evident in our simulations is the isostatic rebound of the orogen (Davis and Blanckenburg 1995) and the beginning of rapid exhumation of buoyant parcels in the orogenic wedge (Fig. 3.14b). Although the actual mechanism and timing of exhumation is beyond the scope of this paper, we highlight the following points: (1) exhumation of rocks in the orogenic wedge is an integral and self-consistent output in our experiments, (2) the orogenic wedge is highly heterogeneous in terms of its rock types (Fig. 3.14a), but with an average composition close to that of the upper crust, (3) the average degree of hydration in the orogenic wedge is high (Fig. 3.14c). Since a large variety of quartzofeldespatic rocks produce granitic melts by dehydration melting at temperatures between 800 and $1,100^{\circ} \mathrm{C}$ (e.g., Patiño Douce and McCarthy 1998), it is likely that at least some of the rocks being exhumed after the breakoff will experience dehydration melting and/or release of water-rich fluids (Vry et al. 2009). Together with the aforementioned observation of partial melting in the mantle, this offers a sound explanation to the common observation of post-collisional bimodal (granitic and basaltic) magmatism (Davis and 


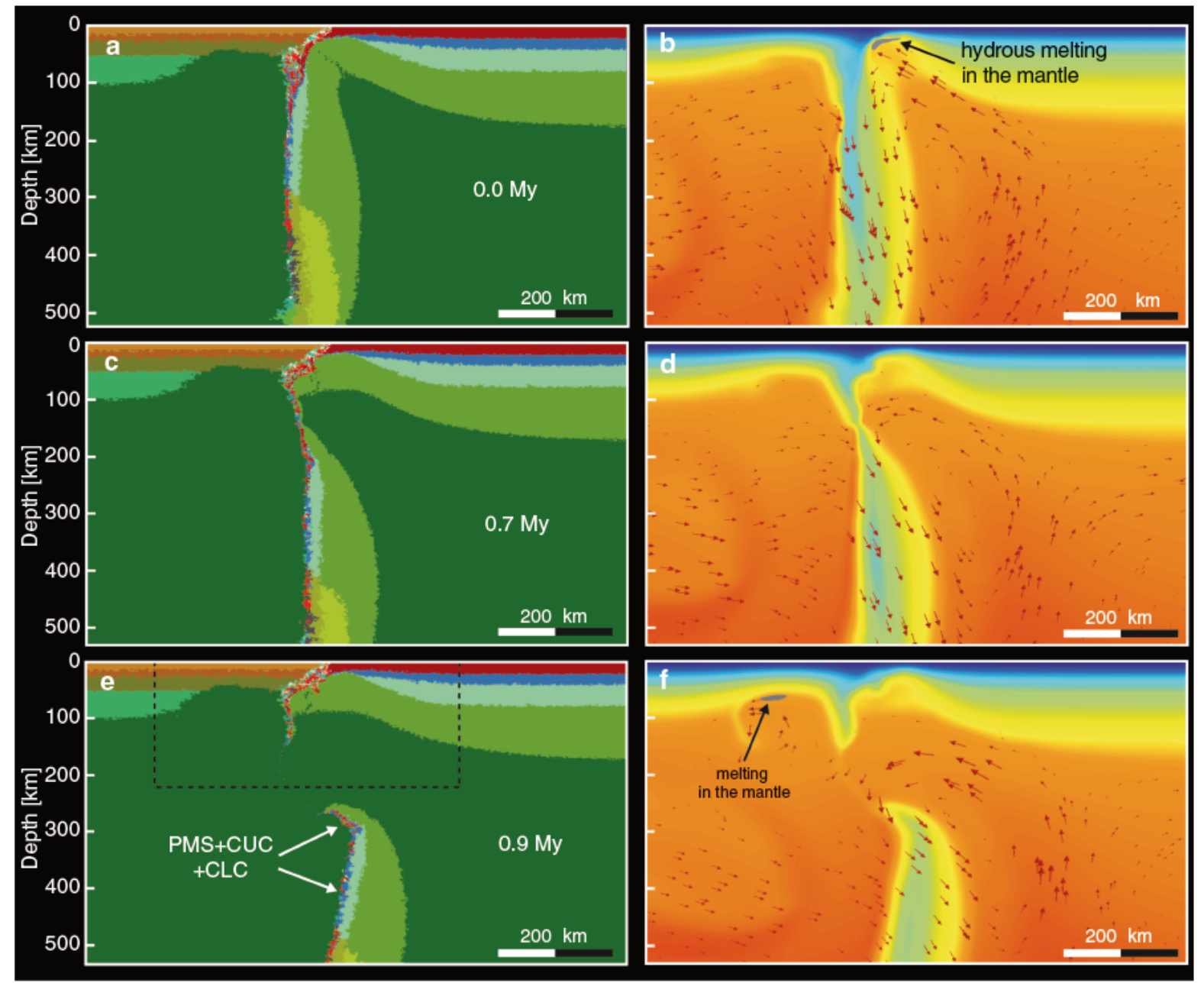

Fig. 3.12 Evolution of a typical slab breakoff in our simulations. Left column shows rock types (scale as in Fig. 1c). Right column depicts the thermal and velocity structures (scale as in Fig. 1a). Dashed box in e refers to the zoom in Fig. 15.

Fig. 3.13 Symmetric necking and slab breakoff arising in a model with extremely strong passive margin (yield stress

$1000 \mathrm{MPa}$ and coefficient of friction 0.8 ). The star indicates the location of the tip of the miogeoclinal prism.

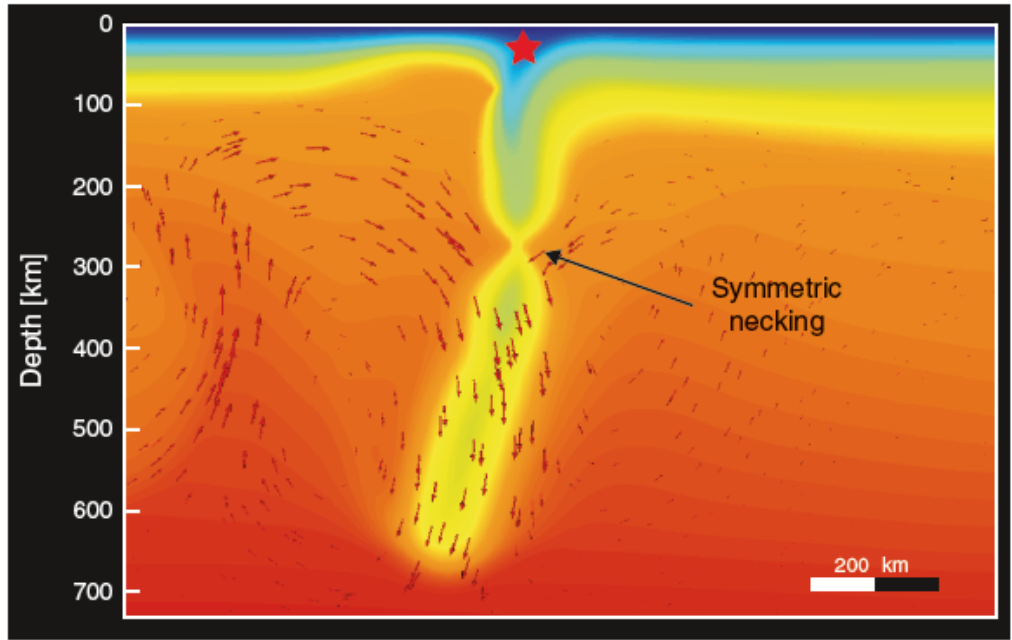



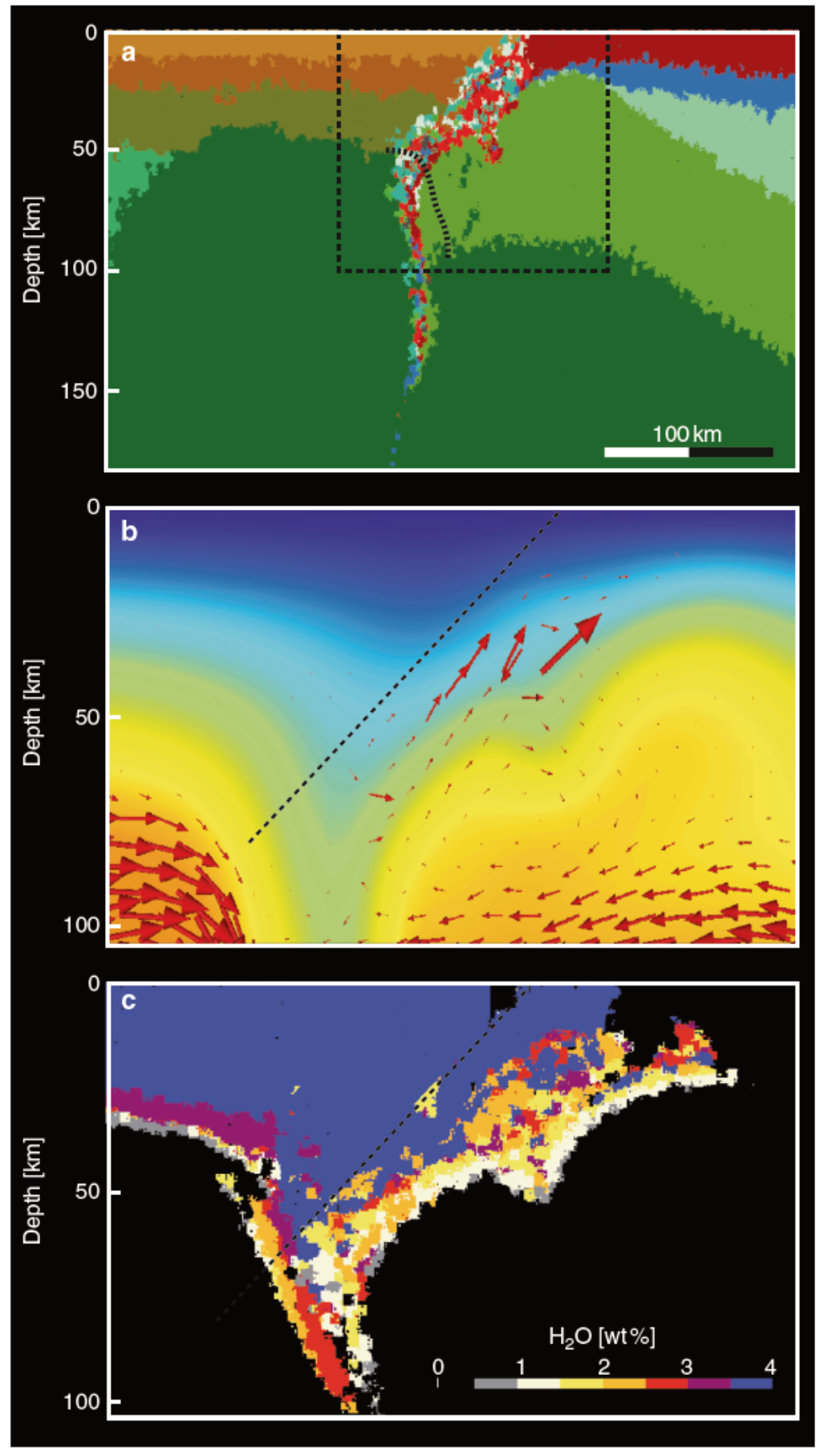

Fig. 3.14 (a) Rock types in the zoom box of Fig. 12e. Note the highly heterogeneous nature of the suture zone. The thick dotted line indicates the portion of the suture that is convectively removed in later times (after $\sim 2.0 \mathrm{My}$ ). The based box refers to the zoom in (b) and (c). (b) Temperature and velocity fields in the suture zone. The dashed line indicates where the boundary between the arc and the suture is. (c) Bound water content in the assemblages. Note that large parts of the suture have water contents $>2 \%$. 
Blanckenburg 1995) and existence of paired seismic and electrical conductivity anomalies in active orogens (Vry et al. 2009).

\subsection{Summary and Conclusions}

In this paper we have used 2D numerical simulations to study the large-scale dynamics of an arc/microcontinent continent collision. We have not imposed velocity boundary conditions to either force or stop continental subduction, and therefore the velocities obtained in our simulations emerge self-consistently from the balance between internal forces in our numerical domain. We have also coupled our thermomechanical solvers to a petrologcial/thermodynamic model, which allowed us to obtain realistic estimates of all relevant physical properties and track metamorphic reactions within a wide range of pressures, temperatures, and bulk compositions.

Although our models are complex enough to capture most of the first-order physical processes relevant to subduction environments, they still are a simplification of reality. Importantly, we have not addressed systematically the role of compositional variations within the continental crust and its original degree of hydration. These two factors could play a significant role in the evolution of the collision and the recycling of continental derived material into the deep mantle. Also, partial melting of crustal lithologies has not been explicitly included in our simulations. Arguably, the latter effect may not be a first order factor in the largescale evolution of the collision, but it is likely relevant in discussions of smaller-scale features across the orogen. Another important factor that has not been included in our study is the effect of the third dimension. Compared to full 3D models, 2D models generally require more energy for the onset and development of certain processes such as slab breakoff or the internal deformation of plates. For instance, the occurrence of a slab breakoff in 3D models typically evolve from a slab tearing instead of a full necking along the slab (e.g., Yoshioka and Wortel 1995). In this sense, the energy involved in our models should be considered an upper bound of that required in real cases.

Despite these limitations, there are a number of significant generalizations that can be made from the results of this investigation. These are:
1. The buoyancy increase due to subduction of continental material may not be the only explanation for the typical decrease in convergence velocity estimated in collisional settings after the arrival of continental crust to the trench. Delamination of the lithospheric mantle at lower crust levels after a period of continental subduction can result in a similar pattern of convergence velocities. This scenario is favoured in settings dominated by slab rollback.

2. The thermal structures of the continental plate and passive margin play important roles in the evolution and final configuration of the collision. The strengthening effect due to the colder temperatures in a thick continental plate overcomes the effects of its extra negative buoyancy. Thus, the overall effect of increasing the thermal thickness of the continental plate is to reduce convergence velocities, stalling subduction, and thus impede deep recycling of continental material.

3. When both the arc and the continental plate are free to move (e.g., bounded by mid-ocean ridges), the system evolves as forward subduction rather than as slab rollback. Although the circulation pattern in the sublithospheric mantle and in the mantle wedge are significantly different between these two cases, the general pattern and absolute values of the resulting convergence velocities are similar. Replenishment of fertile mantle in the mantle wedge and enhanced partial melting is favored in forward subduction scenarios.

4. The composition of the continental lithospheric mantle exerts a moderate influence on the overall evolution of the collision system. Since the highly depleted part of continental mantle seems to be restricted to shallow depths only $(<6080 \mathrm{~km})$, the thermal effect is usually more important and the overall buoyancy of the lithospheric mantle at the beginning of the collision is negative.

5. The rheology of the continental crust is a major factor controlling both the duration of continental subduction and the volume of continental material that can be subducted. Strong crusts favor deep subduction of continental materials while soft crusts tend to accumulate at shallow depths. In the latter case, the decoupling between the upper crust and the rest of the lithosphere effectively restrict the increase of positive buoyancy of the slab, which remains negatively buoyant at all conditions. 
6. Subducted continental crust remains buoyant with respect to the surrounding mantle down to depths of $\sim 250300 \mathrm{~km}$. Potential detachments from the slab will therefore result in upwelling of these continental portions. However, the characteristic cold temperatures in the uppermost part of the slab result in a strong mechanical coupling between the crustal and mantle components, hindering the possibility of detachments.

7. Subducted continental crust that reaches depths $>250300 \mathrm{~km}$ becomes significantly denser than the surrounding mantle due to the appearance of high-density phases. This proves extra negative buoyancy to the slab and inhibit the return of subducted crust to the surface (point of no return).

Acknowledgments We would like to thank the editors D. Brown and P. Ryan for inviting us to contribute to this special volume. We are also indebted to all the participants of the field trip IGCP 524 (Ireland) for stimulating discussions and explana tions in the field. We thank S. Saxena and W. Yong for unself ishly sharing their databases and helping in the implementation of new end members, and G. Ranalli, G. Houseman, and B. Kaus for their detailed reviews and suggestions. Discussions with F. Capitanio, M. Faccenda, S. Turner, T. Rushmere, K. Grant and B. Schaefer were particularly useful. We also thank the team at VPAC and the geodynamics research group at Monash for their support. Most figures were produced with the open source visualization package Paraview. This work has been supported by Macquarie University (JCA) and Monash University (SZ) grants and by the Monash e Research Centre and ITS Research Support Services through the use of the Monash Sun Grid cluster. This is contribution 659 from the Australian Research Council National Key Centre for the Geo chemical Evolution and Metallogeny of Continents (http:// www.gemoc.mq.edu.au).

\section{Appendix A}

\section{A.1 Governing Equations}

The dynamics of the problem analyzed in this paper is governed by the usual conservation equations of fluid dynamics (under the continuum hypothesis), namely the conservation of mass, momentum, and energy (cf. Batchelor 1967; Kundu 1990). The conservation of mass is the most obvious condition and requires

$$
\frac{\partial \rho}{\partial t}+\frac{\partial\left(\rho u_{i}\right)}{\partial x_{i}}=0
$$

where $t$ is time, $\rho$ bulk density, $u_{i}$ velocity, and $x_{i}$ refers to a Cartesian coordinate system. Equation (3.1) is also known as the continuity equation.

The conservation of momentum is the result of applying Newton's law of motion to an infinitesimal fluid element. In its differential form it reads

$$
\rho\left(\frac{\partial u_{i}}{\partial t}+u_{j} \frac{\partial u_{i}}{\partial x_{j}}\right)=\rho g-\frac{\partial P}{\partial x_{i}}+\frac{\partial \tau^{\prime}{ }_{i j}}{\partial x_{j}}
$$

where

$$
\begin{aligned}
\tau_{i j}^{\prime} & =2 \mu\left[\frac{1}{2}\left(\frac{\partial u_{i}}{\partial x_{j}}+\frac{\partial u_{j}}{\partial x_{i}}\right)-\frac{1}{3}\left(\frac{\partial u_{i}}{\partial x_{i}}\right) \delta_{i j}\right] \\
& =2 \mu\left(\epsilon_{i j}-\frac{1}{3} \epsilon_{i i} \delta_{i j}\right)
\end{aligned}
$$

is the deviatoric part of the total stress tensor $\sigma_{i j}=-P \delta_{i j}+\tau_{i j}^{\prime}$ for a Newtonian fluid, $P$ is pressure (i.e., $\left.-1 / 3 \sigma_{i i}\right), g$ the acceleration of gravity, $\mu$ the dynamic shear viscosity, $\delta_{i j}$ the Kronecker delta, and $\varepsilon_{i j}$ the strain rate tensor (cf. Batchelor 1967). Equation (3.2) is the 3D general form of the Navier-Stokes equation of motion. Note that the so-called Stokes assumption, in which the bulk viscosity is neglected, has been adopted in (3.3) (Kundu 1990).

The equation of conservation of energy relevant to our study includes five terms:

$$
\rho \frac{D E}{D t}=\sigma_{i j} \frac{\partial u_{i}}{\partial x_{j}}+H+\rho L s \frac{D \chi}{D t}+\rho L m \frac{D F}{D t}-\frac{\partial q}{\partial x_{i}}
$$

where $E$ the is internal energy per unit mass, $H$ the internal heat generation (volumetric) due to radioactive decay, $L s$ the latent heat of transformation arising from solid-solid phase changes, $L m$ the latent heat of melting, $q$ the conductive heat flow, $\chi$ the mass fraction of the new phase across a divariant solid-state reaction, $F$ the mass fraction of melt, and $D / D t$ refers to the material derivative. The first term in the righthand side of (3.4) is a mechanical contribution due to compressions and deformations of a fluid element without change of its velocity (Batchelor 1967). Using the above definition of total stress tensor $\sigma_{i j}$, (3.4) can be rewritten as

$$
\rho \frac{D E}{D t}=-P \frac{\partial u_{i}}{\partial x_{i}}+\Phi+H+\rho L s \frac{D \chi}{D t}+\rho L m \frac{D F}{D t}-\frac{\partial q}{\partial x_{i}}
$$


where

$$
\Phi=2 \mu\left[\epsilon_{i j}-1 / 3 \frac{\partial u_{i}}{\partial x_{i}} \delta_{i j}\right]^{2}=\tau_{i j}^{\prime} \epsilon_{i j}
$$

is the viscous dissipation through shear deformation [i.e., there are no volume changes associated with the tensor Equation (3.6)], sometimes referred to as "shear heating" in the literature. Using the following thermodynamic identities

$$
\begin{gathered}
T d S=d E+P d V \\
d V=-\frac{d \rho}{\rho^{2}}
\end{gathered}
$$

which imply

$$
\frac{T D S}{D t}=\frac{D E}{D t}-\frac{P}{\rho^{2}} \frac{D \rho}{D t}
$$

we can rewrite (3.5) as

$$
\rho T \frac{D S}{D t}=\Phi+H+\rho L s \frac{D \chi}{D t}+\rho L m \frac{D F}{D t}-\frac{\partial q}{\partial x_{i}}
$$

where we made use of (3.1) to eliminate the terms affected by $P$. Equation (3.7) implicitly includes all the "non-conventional" entropy production terms (e.g., due to phase changes) in the $E$ term. Recalling that for a homogeneous fluid the rate of change of entropy is

$$
\frac{D S}{D t}=\frac{C p}{T} \frac{D T}{D t}-\frac{\alpha}{\rho} \frac{D P}{D t}
$$

we obtain the more familiar form

$$
\begin{aligned}
\rho C p & \left(\frac{D T}{D t}-\frac{T \alpha}{\rho C p} \frac{D P}{D t}\right) \\
= & \Phi+H+\rho L s \frac{D \chi}{D t}+\rho L m \frac{D F}{D t}-\frac{\partial q}{\partial x_{i}}
\end{aligned}
$$

where $\alpha$ is the coefficient of thermal expansion and $C p$ the isobaric specific heat capacity. Since we introduce latent heat effects directly into the energy equation, $\alpha$ and $C p$ do not need to be replaced by their "effective" or "apparent" counterparts in the phase change tem- perature range (e.g., Reddy and Gartling 2000; Li and Gerya 2009). Note that the second term on the lefthand side of (3.12) can be written as

$$
\frac{T \alpha}{\rho C p} \frac{D P}{D t}=\left(\frac{\partial T}{\partial P}\right)_{S} \frac{D P}{D t}=\frac{T \alpha}{\rho C p}\left(\frac{\partial P}{\partial t}+u_{i} \frac{\partial P}{\partial x_{i}}\right)
$$

For the Earth's mantle it is appropriate to neglect the term $\partial P / \partial t$ and assume that the vertical gradient in $P$ is dominant and equal to $\rho g$ (i.e., hydrostatic profile; Schubert et al. 2001). Accordingly, (3.13) becomes

$$
\begin{aligned}
\rho C p\left(\frac{D T}{D t}-\frac{H_{a d}}{\rho C p}\right)= & \Phi+H+\rho L s \frac{D \chi}{D t} \\
& +\rho L m \frac{D F}{D t}-\frac{\partial q}{\partial x_{i}}
\end{aligned}
$$

where $H_{a d} \equiv T \alpha \rho u_{z} g$ is the energy gained/lost by adiabatic compression/decompression and $u_{z}$ is the vertical component of velocity. An alternative useful form of this latter relation is

$$
\begin{aligned}
& \rho C p\left(\frac{\partial T}{\partial t}+u_{i} \frac{\partial T}{\partial x_{i}}\right) \\
& =\frac{\partial}{\partial x_{i}}\left(-k_{i j} \frac{\partial T}{\partial x_{i}}\right)+\Phi+H+H_{a d}+\rho L s \frac{D \chi}{D t}+\rho L m \frac{D F}{D t}
\end{aligned}
$$

where $k_{i j}$ is the thermal conductivity tensor. Equations (3.1), (3.2), and (3.15) represent the fundamental set of equations governing the heat transfer and flow of a compressible Newtonian fluid. The insertion of an equation of state describing density as a function of other intensive variables (e.g., P, T, F, $\chi$ ) completes the definition of the mathematical problem (except for the non-Newtonian case). In what follows, we describe a number of approximations and modifications to the fundamental set of equations.

\section{A.2 Approximations}

We adopt a modified version of the extended Boussinesq approximation (e.g., Christensen and Yuen 1985) in solving the system (3.1), (3.2), and (3.15). The Prandlt $P r$ and Match $M$ numbers of a fluid determine the effects of inertia and compressibility on the flow 
(cf. Jarvis and McKenzie 1980; Schubert et al. 2001). For the Earth's mantle, the product $\operatorname{Pr} M^{2}$ is $\ll 1$ (Jarvis and McKenzie 1980), and therefore the material can be considered incompressible except in regions affected by phase transitions (see below). Equation (3.1) thus becomes

$$
\frac{\partial u_{i}}{\partial x_{i}}=0
$$

Likewise, given the effectively infinite Prandlt number of the mantle, inertia terms in the momentum (3.2) are neglected. Using (3.16), we rewrite (3.2) as

$$
0=\rho g-\frac{\partial P}{\partial x_{i}}+\frac{\partial}{\partial x_{j}}\left[\mu\left(\frac{\partial u_{i}}{\partial x_{j}}+\frac{\partial u_{j}}{\partial u_{i}}\right)\right]
$$

Besides the inertia terms, the only difference between the (3.2) (compressible fluid) and (3.17) (incompressible fluid) is a term that includes the divergence $\nabla=\partial / \partial x_{i}$ of the velocity field

$$
-\frac{\partial}{\partial x_{j}}\left[\frac{2}{3} \mu\left(\frac{\partial u_{i}}{\partial x_{i}}\right) \delta_{i j}\right]
$$

The energy equation is made compatible with (3.16) by removing the term affected by the divergence of velocity in the viscous dissipation term (3.6), which becomes

$$
\Phi=2 \mu \epsilon_{i j}^{2}
$$

The latent heats $L$ in the energy equation can be written as $\Delta S T$, where $\Delta S$ is the entropy change of the phase transformation (solid-solid or solid-melt). Since entropy is an extensive quantity, the magnitude of $\Delta S$ in a rock experiencing a phase transition will depend on the actual amount of matter being transformed. For instance, although the $\Delta S$ associated with the spinelgarnet transformation is $\sim 25 \mathrm{~J} \mathrm{Kg}{ }^{1} \mathrm{~K}^{1}$ in the system $\mathrm{MgAl}_{2} \mathrm{O}_{4}$ (spinel) $+4 \mathrm{MgSiO}_{3}$ (orthopyroxene) $\rightleftarrows$ $\mathrm{Mg}_{3} \mathrm{Al}_{2} \mathrm{Si}_{3} \mathrm{O}_{12}$ (pyrope) $+\mathrm{Mg}_{2} \mathrm{SiO}_{4}$ (forsterite), it becomes only $\sim 4 \mathrm{~J} \mathrm{Kg}^{1} \mathrm{~K}^{1}$ in a natural lherzolite with 4.5 wt $\% \mathrm{Al}_{2} \mathrm{O}_{3}$ (see also Iwamori et al. 1995). Similarly, our thermodynamic calculations (see below) indicate that most metamorphic reactions typically involve $\Delta S<8 \mathrm{~J} \mathrm{Kg}^{1} \mathrm{~K}{ }^{1}$. Such $\Delta S$ values result in local variations of the order of $510^{\circ} \mathrm{C}$ in the thermal structure and thus they can be ignored without losing any generality in large-scale models. On the other hand, reactions involving large mass fractions, such as the olivine-wadsleyite phase transitions in lherzolites ( $\sim 60 \mathrm{vol} \%$ of the rock), can result in $\Delta S$ of the order of $3045 \mathrm{~J} \mathrm{Kg}{ }^{1} \mathrm{~K}^{1}$. In this case, the local thermal perturbation close to the phase transition can be as high as $6070^{\circ} \mathrm{C}$ for fast vertical flow, and therefore the contribution from latent heat release should not be neglected in the energy equation. We introduce latent heat effects by approximating the material derivative of $\chi$ by (no time effects)

$$
\frac{D \chi}{D t} \equiv u_{i} \frac{\partial \chi}{\partial x_{i}}
$$

where $\partial \chi / \partial x_{i}$ is assumed to be a step function (i.e., sharp transition) which is zero everywhere except at the transition, where it takes a value of $1 / u_{i} \Delta t$. Appropriate values of $\Delta S$ are calculated as a function of bulk rock composition using a Gibbs free energy minimization formalism (see below).

The latent heat of melting is addressed in a similar manner, except that in this case the material derivative $D F / D t$ is a continuous function based on a parameterization of partial melting as a function of $\mathrm{P}, \mathrm{T}$, water content, and depletion (see below).

As stated above, the incompressibility assumption (3.16) is appropriate for modelling flow within the Earth as long as the Boussineq assumptions are fulfilled. This is not longer the case when density changes produced by mineral phase transitions are included in the model. Neglecting volume changes associated with phase transitions in the conservation equations has the net effect of "creating/destroying" mass when the material experiences a phase change (i.e., mass conservation is not ensured). This carries the obvious consequence of over/underestimating the buoyancy forces of the model, which in the case of a subducting plate has a major long-term effect on its buoyancy and thus on the dynamics of the model. We tackle this problem by modifying (3.16) and (3.17) to account for compressibility (i.e., non-zero divergence of the velocity field) in the regions affected by phase transitions. Equation (3.16) thus becomes

$$
\frac{\partial u_{i}}{\partial x_{i}}=-\frac{1}{\rho} \frac{\partial \rho}{\partial x_{i}} u_{i} \approx-\frac{1}{\rho} \frac{\Delta \rho}{\Delta t}
$$


where the material change in density $\frac{\Delta \rho}{\Delta t}$ is computed in each Lagrangian particle as the difference between the density in the current and previous time step (we only account for density changes due to mineral phase transitions, density variations related to melting are not included). The application of this non-zero divergence generates a localized velocity field that effectively compresses/expands the material at the time of the transition, therefore enforcing local mass conservation. In practice, since our numerical box is closed, we apply the mass correction only to lithospheric materials. This plays the role of simulating an "open" domain (i.e., sublithospheric convecting mantle can flow through the boundaries of the box to compensate for lithospheric volume changes). We note that this correction is not equivalent to modelling a fully compressible material, but rather numerically impose the changes in volume needed to conserve the mass in specific regions of the simulation domain, i.e., lithospheric materials. Similar strategies have been used by (e.g., Warren et al. 2008; Burov and Yamato 2008).

Equations (3.16) through (3.20) are solved using the finite-element platform Underworld (Moresi et al. 2003), which has been modified accordingly to account for all the processes described in this paper. The numerical accuracy of the mass correction term included in (3.20) is evaluated in each simulation by keeping track of the mass of the subducting plate trough time. However, this calculation is not trivial due to the difficulty in estimating the volumes of all bodies (i.e., the geometry of a body is defined by a set of moving particles that tend to mix with the particles of surrounding materials during the evolution of the model). We circumvent this problem by constructing Voronoi diagrams based on the particles and computing the mass of each particle as the product of its density times the area of the corresponding Voronoi cell. Therefore, the mass of a body is simply the sum of the mass of its constituents particles. We find that typical accumulated errors associated with mass conservation are $<1 \%$.

\section{A.3 Rheological Relationship}

Our numerical models have both plastic (brittle) and viscous (Newtonian and non-Newtonian) rheologies.
The brittle behaviour of rocks is assumed to follow a modified version of the von Mises criterion, in which the material yields (plastically) when the following condition is met

$$
\sqrt{\tau^{\prime}}{ }_{I I} \geq c_{0}+\mu(\rho g z)
$$

where $\tau_{I I}^{\prime}$ is the second invariant of the deviatoric stress tensor, $c_{0}$ is the "cohesive strength" and $\mu$ the coefficient of internal friction. Parameters $c_{0}$, and $\mu$ are specific for each material and vary among simulations. High-pressure failure of rocks (e.g., Shimada 1993; Renshaw and Schulson 2004) is modelled assuming a critical (constant) yield stress $\tau_{c}$ between 250 and $350 \mathrm{MPa}$ (See Fig. 3.2).

The assumed general flow law for both diffusion and dislocation mechanisms has the following form (e.g. Hirth and Kohlstedt 2003)

$$
\dot{\epsilon}=A(\sigma)^{n} d^{m} \Psi_{H_{2} O} \exp \left(-\frac{E^{*}+P V^{*}}{R T}\right)
$$

where $d$ is the average grain-size, $\sigma$ the differential stress, $A$ the pre-exponential factor, $n$ the stress exponent, $m$ the grain-size exponent, $E^{*}$ the activation energy, $V^{*}$ the activation volume, $R$ the gas constant, and $\Psi_{\mathrm{H}_{2} \mathrm{O}}$ a parameter dependent on the water content (see below). Note that the activation energy $E^{*}$ and volume $V^{*}$ already include the $T$ and $P$ dependence of $\mathrm{OH}$ dissolution in olivine (cf. Hirth and Kohlstedt 2003; Karato 2008). Applying the Levy-von Mises formalism to purely viscous fluids (Ranalli 1995; Karato 2008) allows defining the effective viscosity as

$$
\eta=\frac{1}{2}\left(\tau_{E}^{\prime}\right)^{1}{ }^{n} A{ }^{1}=\frac{1}{2}\left(\dot{\epsilon}_{E}\right)^{\frac{1 n}{n}} A \frac{1}{n}
$$

where $\tau_{E}^{\prime}$ and $\dot{\epsilon}_{E}$ are the "effective" second invariants of the deviatoric stress tensor $\left[=\left(\frac{1}{2} \tau_{i j}^{\prime} \tau_{i j}^{\prime}\right)^{1 / 2}\right]$ and of the strain rate tensor $\left[=\left(\frac{1}{2} \dot{\epsilon}_{i j} \dot{\epsilon}_{i j}\right)^{1 / 2}\right]$, respectively. Parameter $A$ is a factor derived from the empirical Equation (3.22) and the type of experiment [for details see Chap. 4 of Ranalli (1995) and Chap. 3 of Karato (2008)]. All relevant parameters used to solve (3.21) (3.23) are listed in Table 3.3.

Since diffusion and dislocation creep are thought to act simultaneously in the mantle, two different viscosities $\eta_{\text {diff }}$ and $\eta_{\text {disl }}$ are computed separately and then 
combined into an effective viscosity $\eta_{\text {eff }}$. The latter is computed as the harmonic mean of $\eta_{\text {diff }}$ and $\eta_{\text {disl }}$ :

$$
\frac{1}{\eta_{\mathrm{eff}}}=\left(\frac{1}{\eta_{\mathrm{diff}}}+\frac{1}{\eta_{\mathrm{disl}}}\right)
$$

This expression is truncated if the resulting viscosity is either greater or lower than two imposed cutoff values $\left(10^{18}\right.$ to $\left.10^{24} \mathrm{~Pa} \mathrm{~s}\right)$. Although grain-size may change due to grain growth and dynamic recrystallization processes, its dependence on mantle flow conditions is poorly known and therefore we consider only constant grain sizes. For average grain sizes $d \gtrsim 3.5 \mathrm{~mm}$, dislocation creep represents an important component of the effective viscosity at depths $<200 \mathrm{~km}$. For smaller values of $d$, diffusion creep becomes dominant. In this context, we note that synthetic seismological models of oceanic mantle suggest $d \gtrsim 3.5 \mathrm{~mm}$ (Afonso et al. 2008a, b). All simulations shown in this work are carried out with a constant $d=5 \mathrm{~mm}$.

\section{A.4 Melting Model}

We adopt a simple melting model based on the parameterizations of Katz et al. (2003). Melting of crustal components are not considered in the present work. The melt fraction of mantle rocks as a function of $\mathrm{P}, \mathrm{T}$, water content, and depletion $\xi$ is expressed as

$$
F_{\left(T, P, H_{2} O, \xi\right)}=\left(\frac{T-T_{s}}{T_{l}-T_{S}}\right)^{\beta 1}
$$

where

$$
\begin{aligned}
& T_{s}=A_{1}+A_{2} P+A_{3} P^{2}-\Delta T_{w}+\Delta T_{\xi} \\
& T_{l}=B_{1}+B_{2} P+B_{3} P^{2}-\Delta T_{w}+\Delta T_{\xi}
\end{aligned}
$$

Parameters $A_{n}$ and $B_{n}$ are fitting parameters obtained from regressions through a large number of experimental data (Katz et al. 2003). $\Delta T_{w}$ is a parameter that takes into account the temperature decrease in the solidus caused by the presence of water and has the simple form (Katz et al. 2003)

$$
\Delta T_{w}=K X_{H_{2} O}^{\gamma}
$$

where $K=43^{\circ} \mathrm{C}$ wt $\% \gamma, \gamma=0.75$, and $X_{\mathrm{H}_{2} \mathrm{O}}$ is the weight percent of water in the melt. The latter is obtained assuming batch melting and a representative bulk partition coefficient $D_{w}$ (Katz et al. 2003). Although it is expected that in natural systems $D_{w}$ will vary with $\mathrm{P}, \mathrm{T}$, and bulk composition, here we adopt a constant $D_{w}=0.008$ as a representative average for our simulations; this value is in agreement with various experimental estimations (cf. Hirschmann 2006). The concomitant extraction of bound water during melting of hydrous assemblages is tracked using the same bulk partition coefficient $D_{w}$ as above.

In our simulations we assume "instantaneous" batch melting during each time step. Thus, all melt generated during a time step is extracted in the next time step, except for a small amount that remains in the solid assemblage as residual porosity (see below). The $\Delta T_{\xi}$ parameter is introduced here to include the effect of incremental depletion on the solidus temperature. This effect, not considered in the original parameterization of Katz et al. (2003), arises due to the progressive extraction of fusible elements from the solid rock by partial melting, which in turn increases the solidus temperature of the solid residue. We adopt the following linear form

$$
\Delta T_{\xi}=250 F
$$

where the result is in ${ }^{\circ} \mathrm{C}$ and $F$ is in weight fraction (e.g., $0<F<1$ ). The numerical value 250 is identical to that estimated by Phipps Morgan (2001) and used by Afonso et al. (2008a). The effect of melt depletion on bulk density is accounted for by tracking the total amount of melt extraction $F_{T}$ experienced by mantle particles and applying the following correction: $\rho_{r}=\rho_{s}-\zeta F_{T}$, where $\rho_{r}$ is the bulk density of the residual peridotite, $\rho_{s}$ is the bulk density of the unmelted (fertile) mantle, and $\zeta$ is a correction factor $=2 \mathrm{~kg} \mathrm{~m}^{3} \% F^{1}$. For instance, if a mantle parcel has experienced a total of $10 \%$ melt extraction at a certain time of the simulation, the density of the residual solid assemblage will be $20 \mathrm{~kg} \mathrm{~m}^{3}$ less than its fertile counterpart at identical P-T conditions.

The density of the partially melted rock is computed as

$$
\rho_{\text {eff }}=\rho_{s}(1-F)+\rho_{m} F
$$


where $\rho_{s}$ is the density of the solid aggregate and $\rho_{m}$ is the density of the melt. The former is retrieved from the energy minimization scheme; the latter is estimated as a linear function of $\mathrm{P}$ and $\mathrm{T}$ according to the relation

$$
\rho_{m}=\rho_{0}+\left(\frac{\partial \rho_{0}}{\partial T}\right)_{P}\left(T-T_{0}\right)+\left(\frac{\partial \rho_{0}}{\partial P}\right)_{T}\left(P-P_{0}\right)
$$

where $\rho_{0}$ is a reference value at $P_{0}=1$ atm and $T_{0}=800 \mathrm{~K}$. The derivatives are estimated using themethod of Lange and Charmichael (1987) for a melt with an average $\mathrm{MgO}$ content of $10 \mathrm{wt} \%$. The results are $\left(\partial \rho_{0} / \partial T\right)_{P} \sim-10^{4} \mathrm{~kg} \mathrm{~m}^{3} \mathrm{~K}^{1}$ and $\left(\partial \rho_{0} / \partial P\right)_{T}$ $\sim 0.065 \mathrm{~kg} \mathrm{~m}^{3} \mathrm{Gpa}{ }^{1}$. We assume the existence of a critical residual porosity $F_{c}$ below which melts are immobile (Wark et al. 2003). Here we use a conservative value of $1 \%$ for $F_{c}$. When the calculated $F$ at a certain $\mathrm{P}-\mathrm{T}-\mathrm{H}_{2} \mathrm{O}$ condition becomes greater than $F_{c}$, the "excess" melt (i.e., $F-F_{c}$ ) is extracted from the solid and transported instantaneously to the surface. This assumption is entirely justified by the high velocities of melts in the mantle wedge (e.g., Turner et al. 2001) in comparison to the duration of a typical time step in our simulations $(50,000200,000$ years $)$.

\section{A.5 Darcy Flow of Water}

Aqueous fluids released by dehydration reactions are assumed to migrate through the solid matrix as porus flow along the solid grain boundaries (Darcy's flow). The effect of adding water into nominally-anhydrous minerals by diffusion is neglected here due to its minute contribution to the water balance compared to hydration/dehydration reactions.

Neglecting compaction effects and assuming that pressure variations from the lithostatic state are small (Burov and Yamato 2008), the fluid (melt or aqueous) velocity relative to the matrix velocity obeys the relation

$$
V_{f}-V_{s}=\frac{\Delta \rho g k_{\phi}}{\mu_{f} \phi}
$$

$V_{f}$ and $V_{s}$ are the velocities of the fluid and solid matrix, respectively, $\phi$ the fluid fraction, $\mu_{f}$ the dynamic viscosity of the fluid, and $\Delta \rho$ the density difference between the solid aggregate and the fluid. The permeability $k_{\phi}$ is given by (Wark et al. 2003)

$$
k_{\phi}=\frac{d^{2} \phi^{3}}{270}
$$

where $d$ is the mean grain diameter $(5 \mathrm{~mm})$. As stated in (3.32), the densities and viscosities of the aqueous fluids are required to compute their velocities. Here we estimate the density with the Pitzer-Sterner equation of state for pure water (Pitzer and Sterner 1994). This assumption will underestimate the real density of fluids as the solubility of silica-rich components in water increases significantly at high pressures (Audetat and Keppler 2004), thus increasing the density of the fluid. The viscosities are somewhat more problematic due to their order-of magnitude variations over conditions pertaining to the mantle wedge (Audetat and Keppler 2004). In order to avoid overcomplicating the model with poorly constrained parameters, here we assume the viscosities of fluids to be constants and equal to $1 \mathrm{~Pa}$.

\section{A.6 Thermodynamic Databases and Free Energy Minimization Strategy}

We compute stable assemblages and all their relevant bulk properties ( $\rho, C_{p}, \alpha$, bulk modulus, etc.) by free energy minimization using the software Perple $\mathrm{X}$ (Connolly 2009). All calculations were performed in the system $\mathrm{K}_{2} \mathrm{O} \mathrm{Na}_{2} \mathrm{O} \mathrm{TiO}_{2} \mathrm{FeO} \mathrm{CaO} \mathrm{MgO}$ $\mathrm{Al}_{2} \mathrm{O}_{3} \quad \mathrm{SiO}_{2}+\mathrm{H}_{2} \mathrm{O}$ (KNTFCMAS $+\mathrm{H}_{2} \mathrm{O}$ ), which accounts for $\gtrsim 99 \mathrm{wt} \%$ of the Earth's crust and mantle. All stable assemblages and relevant physical properties were computed a priori as function of $P, T$, bulk composition, and water content and saved in "lookup" tables with a spacing of $75 \mathrm{MPa}$ for $P, 5.6 \mathrm{~K}$ for $T$, and $1 \mathrm{wt} \%$ for water content. Given the size of our numerical domain and the large range of compositions, we used two different thermodynamic databases and formalisms. For ultramafic upper mantle lithologies and for all crustal materials, we used an augmented-modified version of the Holland and Powell (1998) database (revised in 2002). The original data set has been augmented with the following phases: 
$\mathrm{CAS}^{*}\left(\mathrm{CaAl}_{4} \mathrm{Si}_{2} \mathrm{O}_{11}\right), \quad \mathrm{K}$-hollandite* $\left(\mathrm{KAlSi}_{3} \mathrm{O}_{8}\right)$, Si-wadeite* $\left(\mathrm{K}_{2} \mathrm{Si}_{4} \mathrm{O}_{9}\right)$, K-Cymrite* $\left(\mathrm{KAlSi}_{3} \mathrm{O}_{8} \cdot \mathrm{H}_{2} \mathrm{O}\right)$, Mg-majorite $\left(\mathrm{Mg}_{4} \mathrm{Si}_{4} \mathrm{O}_{12}\right)$, Na-majorite $\left(\mathrm{Na}_{2} \mathrm{Al}_{2}\right.$ $\left.\mathrm{Si}_{4} \mathrm{O}_{12}\right)$, Ca-perovskite* $\left(\mathrm{CaSiO}_{3}\right), \mathrm{Mg}$-wadsleyite $\left(\mathrm{Mg}_{2} \mathrm{SiO}_{4}\right)$, Fe-wadsleyite $\left(\mathrm{Fe}_{2} \mathrm{SiO}_{4}\right)$, high-pressure (C2/c) clinoferrosilite $\left(\mathrm{Fe}_{4} \mathrm{Si}_{4} \mathrm{O}_{12}\right)$, and high-pressure $(\mathrm{C} 2 / \mathrm{c})$ clinoenstatite $\left(\mathrm{Mg}_{4} \mathrm{Si}_{4} \mathrm{O}_{12}\right)$; * denotes stoichiometric phases (i.e., not part of a solid-solutions). The so-called NAL and Egg phases as well as Ca-ferrite are stable at very high-pressures along subduction P-T paths (e.g., Ono 1999; Miyajima et al. 2001). However, they are not included in the present version of the database due to their small volume fraction in comparison with other dominant phases.

In order to obtain a reliable internally consistent data set within the system KNTFCMAS $+\mathrm{H}_{2} \mathrm{O}$ for the wide range $0<P<30 \mathrm{GPa}$ and $273<T$ $<2,000 \mathrm{~K}$, the following phases in the original Holland and Powell (1998) database had to be slightly modified (always within experimental uncertainty): forsterite, fayalite, ferrosilite, enstatite, stishovite, tschermakite, Ca-tschermakite, Mg-tschermakite, grossular, pyrope, diopside, and A-phase. The modification involved mainly a refitting of the polynomials describing $C_{p}$ and $\alpha$ to make them compatible with high-pressure experiments, and in some cases a slight modification of the enthalpies of formation and molar volumes. However, we stress that the predictions of the original database at low and moderate (crustal and shallow upper mantle) T-P conditions were not affected to any significant extent by these modifications, since they mostly apply at high-pressure conditions. A full description of all solid-solution models and end-members will be published elsewhere (Afonso and Zlotnik, in preparation).

Our database has been calibrated based on experimental results in simplified systems. The thermodynamic parameters of the mentioned phases were refined in successive steps in a hierarchical manner. First, a consistent database was obtained for the MS, FS, MAS, and FAS systems. Succeeding refining stages considered the ternary systems KAS, CAS, FMS, CMS, and quaternary systems KAS $+\mathrm{H}_{2} \mathrm{O}$, CMAS, FMAS. A subsequent comparison against experimental results in complex system such as NKCMFAS, KNTFCMAS $+\mathrm{H}_{2} \mathrm{O}$, and $\mathrm{KCMAS}+\mathrm{H}_{2} \mathrm{O}$ showed good agreement, and permitted a final refining of some phases and/or solutions (e.g., garnets and clinopyroxenes). Figure 3.15 shows a comparison of calculated phase diagrams for a peridotite using three different databases. It can be seen that at low P-T conditions our database (Fig. 3.15b) predicts similar equilibrium assemblages than the original database of Holland and Powell (1998) (Fig. 3.15a). At higher pressures, however, the original database fails to predict representative assemblages due to the lack of solid solution models for the solubility of pyroxenes into garnet, the transformation of olivine into wadsleyite, and the high-pressure monoclinic polymorph of orthopyroxene with $\mathrm{C} 2 / \mathrm{c}$ symmetry. At high P-T conditions our phase diagram is therefore more similar to that predicted from the high-pressure database of $\mathrm{Xu}$ et al. (2008) (Fig. 3.15c).

Figure 3.16 shows the high T-P experimental results of Irifune and Isshiki (1998) together with predictions from our database for the same P-T and compositional conditions. Although the agreement with the experimental data is good, there are some differences at high pressures. Firstly, the experiments of Irifune and Isshiki (1998) did not constrain the amount of the monoclinic (clinopyroxene-structured) polymorph of orthopyroxene (e.g., Woodland and Angel 1997; Akashi et al. 2009), and therefore we cannot constrain well the effect that the presence (and disappearance) of the $\mathrm{C} 2 / \mathrm{c}$ phase will have on the transfer of atomic species between garnet and clinopyroxene (see also Fig. 3.15). Although the behaviour of the $\mathrm{C} 2 / \mathrm{c}$ phase in our calculations is in perfect agreement with experiments in the simple system FMS, it is still uncertain how this phase behaves in more complex systems such as the one in Fig. 3.16. Secondly, our database predicts high pressure garnets $(\mathrm{P}>10 \mathrm{GPa})$ with relatively low contents in $\mathrm{Na}$ and high in Fe with respect to experiments on continental crust compositions (Irifune et al. 1994; Wu et al. 2009). Clinopyroxene, on the other hand, tend to be deficient in $\mathrm{Fe}$ and $\mathrm{Mg}$. Although we have modified some end-member properties to make the database more reliable at high pressures, the above observations suggest that the solution models adopted in this study from experiments at low-moderate pressures require further refinements. Unfortunately, there are only a few high-P-T experiments in complex systems that could be used for this purpose, and not all of them are consistent (e.g., Irifune et al. 1994; Wu et al. 2009). Despite this limitation, Figs. 3.16 and 3.17 shows that our database reproduce high-P-T experimental observations satisfactorily for a wide range of compositions. 
a

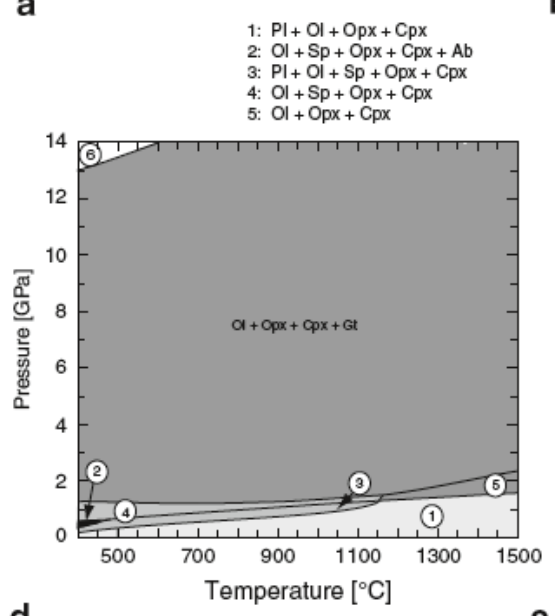

d

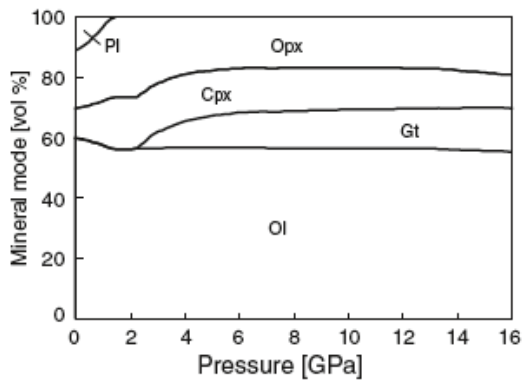

b

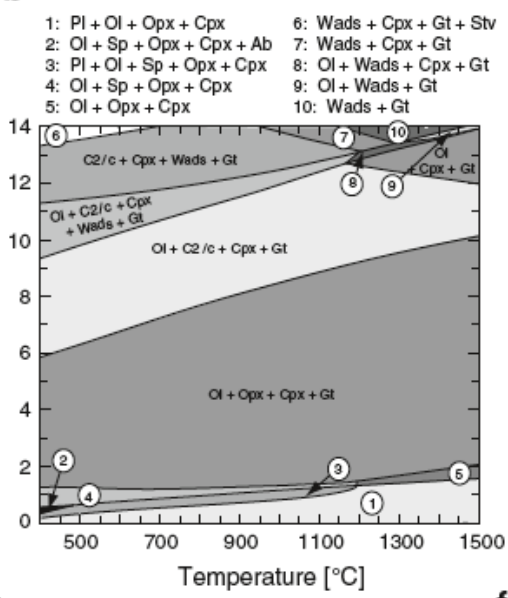

e

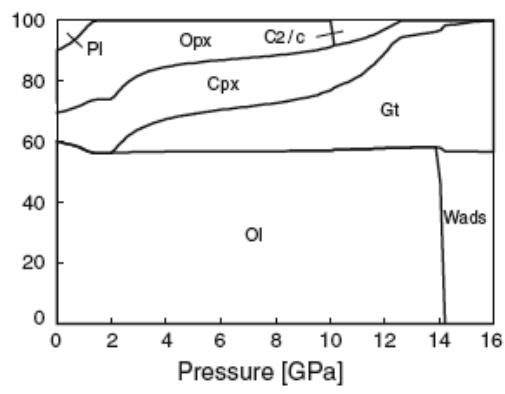

c

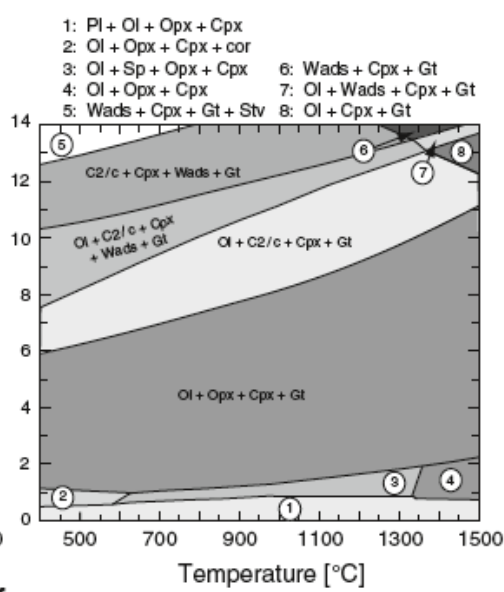

f

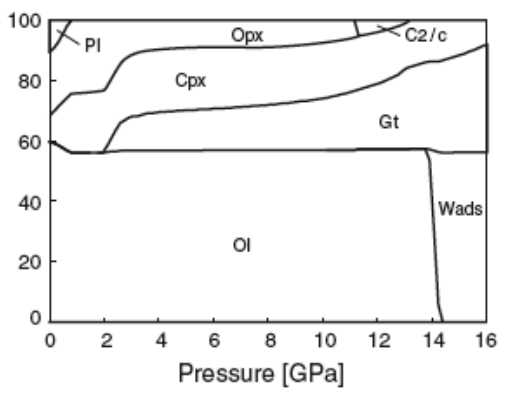

Fig. 3.15 Predicted phase diagrams of dry peridotite using the database of Holland and Powell (1998) (a), our augmented/modified version (b), and the database of Xu et al. (2008) (c). (d), (e) and (f) are the respective modal proportions along a $1330{ }^{\circ} \mathrm{C}$ adiabat.

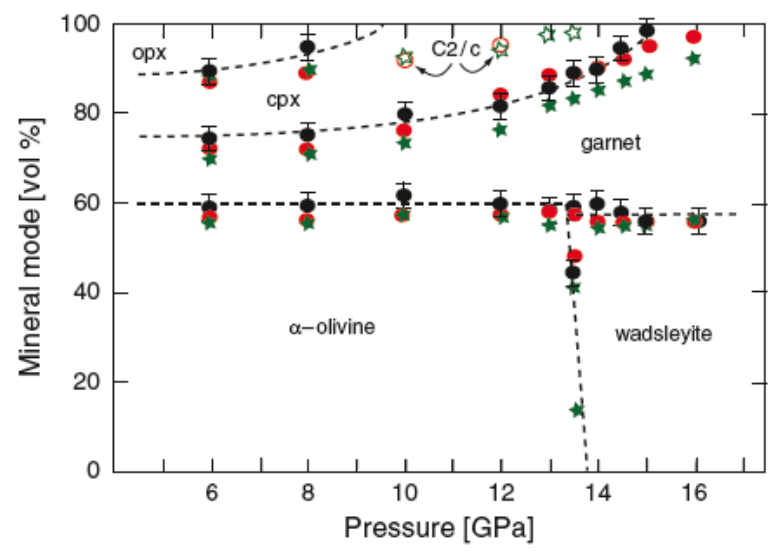

Fig. 3.16 Comparison between experimental and theoretical phase proportions in dry pyrolite. Black circles with error bars are from Irifune and Ito (1998) based on high T P experiments.

The above discussion indicates that our database will predict reliable phase diagrams up to $\$ 30 \mathrm{GPa}$ only for felsic, intermediate, and mafic compositions. For ultramafic compositions, however, predictions are
Red (grey) circles are predictions from our dataset. Stars are predictions from the dataset of $\mathrm{Xu}$ et al. (2008).

only reliable up to $\sim 15 \mathrm{GPa}$ (i.e., above the wadsleyiteringwoodite transition). Therefore, for mantle materials below this transition we use the thermodynamic database and formalism of Xu et al. (2008). This database 
a

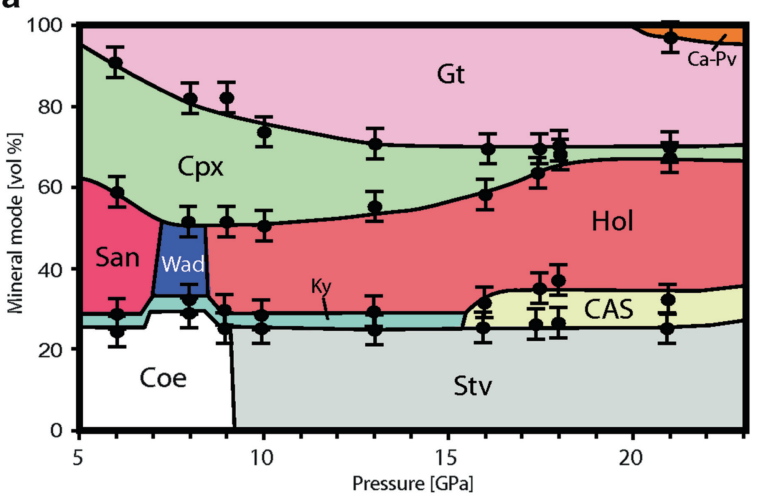

C

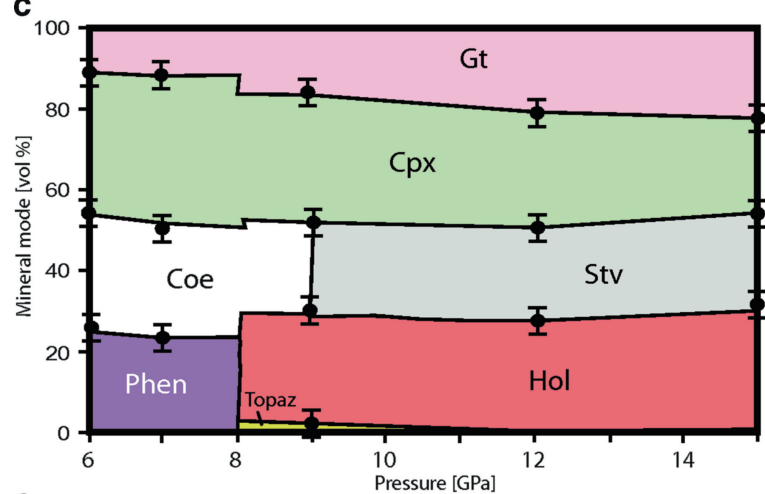

e

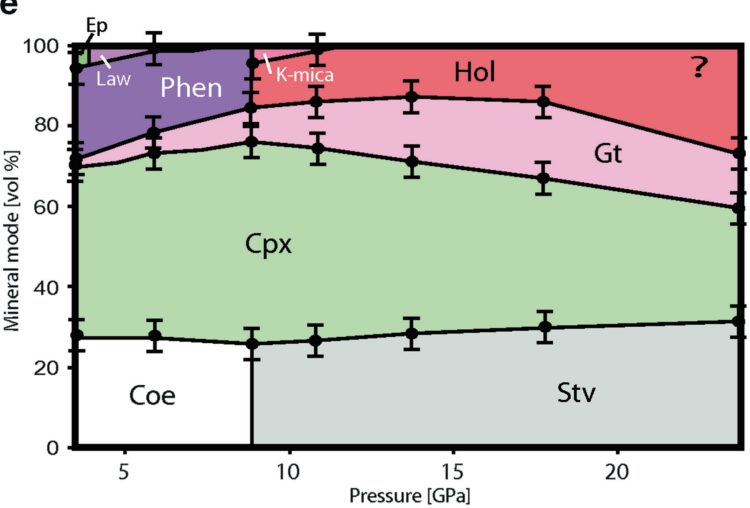

g

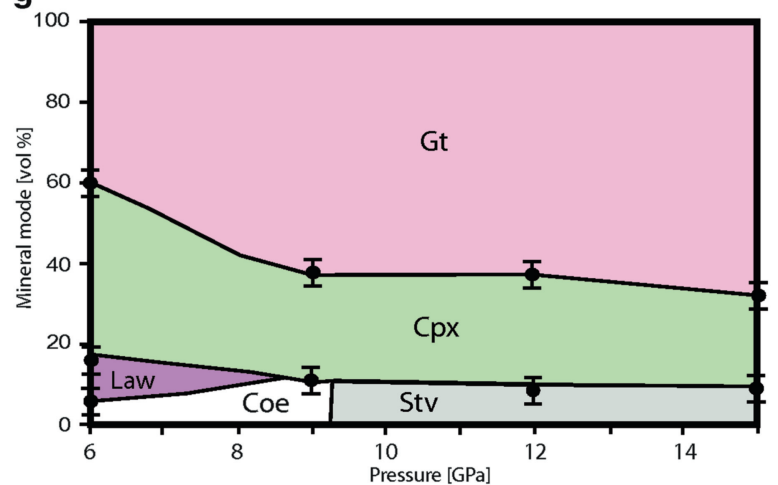

b

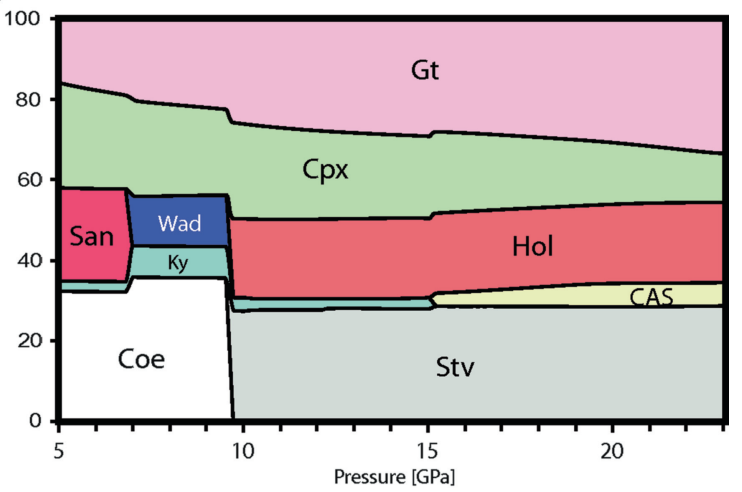

d

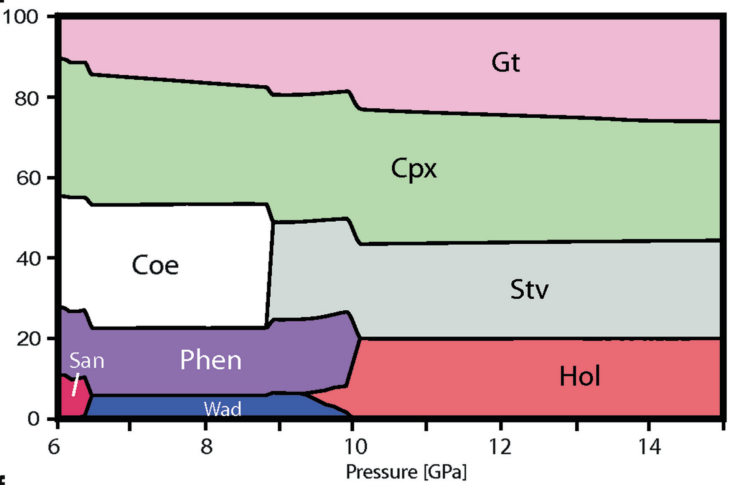

f

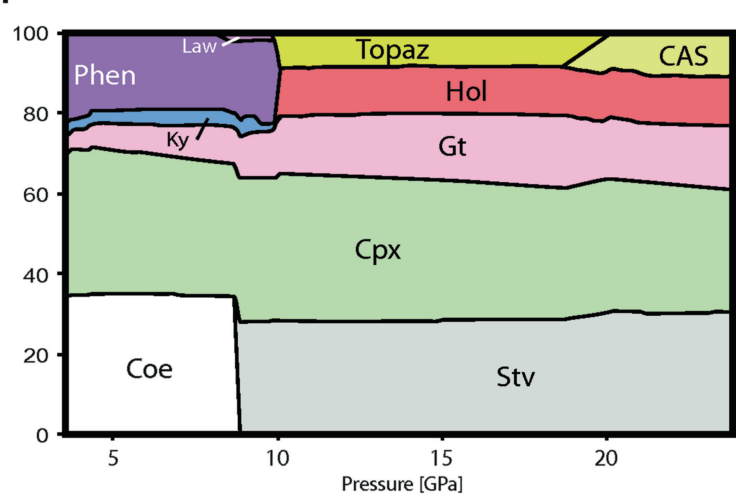

h

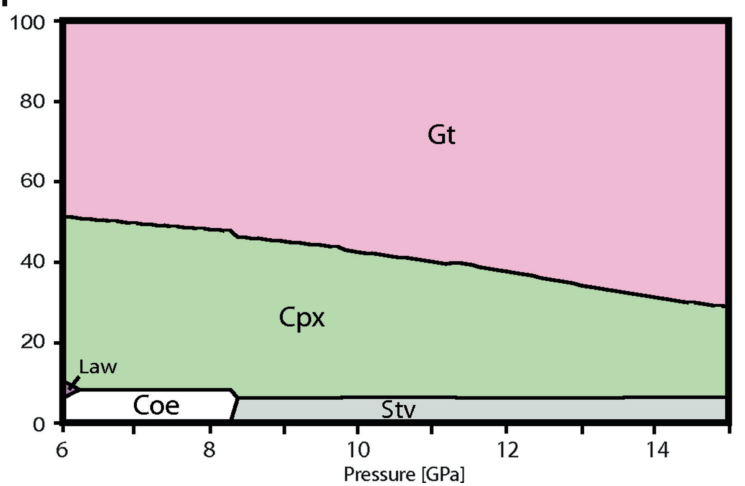

Fig. 3.17 Comparison between experimental results (left column) and predictions from our dataset (right column). Experimental studies are (a) Irifune et al. (1994), (c) Ono (1998), (e) Wu et al. (2009), (g) Ono (1998). 
is suitable for ultramafic compositions (but not for felsic, intermediate, or hydrated compositions) at transition zone and lower mantle conditions in the simplified system NCFMAS. For similar NCFMAS compositions, the differences in bulk $\rho, \alpha$, and seismic velocities between the two databases are $<1 \%$, $\leqslant 1.5$, $<0.8 \%$, respectively. Therefore, the discontinuity of such properties when passing from our database to that of Xu et al. (2008) is unlikely to have any significant effect on the dynamics of the system. In practice, we combine both databases at the Ol-Wads transition, where the properties of the system have a natural and significant discontinuity (i.e., the so-called 410d). We apply an interpolation function to smooth out the sharp contrasts in the physical properties.

\section{References}

Afonso JC, Ranalli G (2004) Crustal and mantle strengths in continental lithosphere: is the jelly sandwich model obso lete? Tectonophysics 394:221 232

Afonso JC, Fernàndez M, Ranalli G, Griffin W, Connolly J, (2008a) Integrated geophysical petrological modelling of the lithospheric sublithospheric upper mantle: methodol ogy and applications. Geochem Geophys Geosyst 9. doi:10.1029/2007GC001834

Afonso JC, Zlotnik S, Fernàndez M (2008b) The effects of compositional and rheological stratifications on small scale convection under the oceans: implications for the thickness of oceanic lithosphere and seafloor flattening. Geophys Res Lett 35:L20308. doi:10.1029/2008GL035419

Afonso JC, Ranalli G, Fernndez M, Griffin W, O'Reilly S, Ulrich F (2010) On the vp/vs mg correlation in mantle peridotites: implications for the identification of thermal and compositional anomalies in the upper mantle. Earth Planet Sci Lett 289:606 618

Ague J (2003) Fuid flow in the deep crust. In: Rudnick RL, Holland HD, Turekian KK (eds) The crust, vol 3, Treatise on geochemistry. Elsevier, Oxford, pp 195228

Akashi A, Nishihara Y, Takahashi E, Nakajima Y, Tange Y, Funakoshi K (2009) Orthoenstatite/clinoenstatite phase transformation in $\mathrm{MgSiO} 3$ at high pressure and high tem perature determined by in situ $\mathrm{X}$ ray diffraction: implica tions for nature of the X discontinuity. J Geophys Res 114 : B04206. doi:10.1029/2008JB005894

Audetat A, Keppler H (2004) Viscosity of fluids in subduction zones. Science 303:513 516

Batchelor GK (1967) An introduction to fluid dynamics. Cam bridge University Press, UK

Beaumont C, Jamieson RA, Butler JP, Warren CJ (2009) Crustal structure: a key constraint on the mechanism of ultra high pressure rock exhumation. Earth Planet Sci Lett 287: 116129
Behn M, Kelemen P (2003) The relationship between seismic $\mathrm{P}$ wave velocity and the composition of anhydrous igneous and meta igneous rocks. Geochem Geophys Geosys 4:1041. doi:10.1029/2002GC000393

Burov E, Yamato P (2008) Continental plate collision, p t t z conditions and unstable vs stable plate dynamics: insights from thermomechanical modelling. Lithos 103:178 204

Capitanio F, Morra G, Goes S, Weinberg R, Moresi L (2010) India sia convergence driven by the subduction of the greater indian continent. Nature Geosci 3. doi: 10.1038/NGEO725

Carlson RW and Miller (2003) Bound water content of the lower oceanic crust estimated from modal analyses and seismic velocities of oceanic diabase and gabbro. Geophys Res Lett RG1001.

Carlson RL, Miller D (2003) Mantle wedge water contents estimated from seismic velocities in partially serpentinized peridotites. Geophys Res Lett 30. doi:10.1029/2002GL016600

Chopin C (2003) Ultrahigh pressure metamorphism: tracing continental crust into the mantle. Earth Planet Sci Lett 212:1 14

Christensen U, Yuen D (1985) Layered convection induced by phase transitions. J Geophys Res 90:10291 10300

Clift P, Vannucchi P (2004) Controls on tectonic accretion versus erosion in subduction zones: implications for the origin and recycling of the continental crust. Rev Geophys 42, RG2001. doi:10.1029/2003RG000127

Connolly JAD (2009) Geodynamic equation of state: what and how. Geochem Geophys Geosyst 10, Q10014. doi:10.1029/ 2009GC002540

Dahlen F.A, Suppe J (1988) Mechanics, growth, and erosion of mountain belts. In: Clark S.P, Jr., Burchfield B.C, and Suppe J (eds) Processes in continental lithospheric deforma tion. Geol. Soc. Am. Spec. Pap., 218:161 178

Davis J, Blanckenburg F (1995) Slab breakoff: q model of lithosphere detachment and its test in the magmatism and deformation of collisional orogens. Earth Planet Sci Lett 129:85 102

Davis J, Blanckenburg F (1998) Thermal controls on slab break off and the rise of high pressure rock during continental collisions. In: Hacker B, Liou J (eds) When continents col lide. Dordrecht, Kluwer, pp 97115

Dewey JF (2005) Orogeny can be very short. Proc Natl Acad Sci USA 102:15286 15293

Dobrzhinetskaya LF, Green HW (2007) Experimental studies of mineralogical assemblages of metasedimentary rocks at earths mantle transition zone conditions. J Metam Geol 25:83 96

Ernst W, Liou J (2008) High and ultrahigh pressure metamor phism: past results and future prospects. Am Mineral 93:1771 1786

Faccenda M, Minelli G, Gerya T (2009) Coupled and decoupled regimes of continental collision: numerical modeling. Earth Planet Sci Let 278:337 349

Fernàndez M, Afonso J, Ranalli G (2010) The deep lithospheric structure of the Namibian volcanic margin. Tectonophysics 481:68 81

Fullea J, Fernàndez M, Afonso JC, Vergés J, Zeyen H (2010) The structure and evolution of the lithosphere asthenosphere boundary beneath the Atlantic Mediterranean transition region. Lithos 120(1 2):74 95

Geoffroy L (2005) Volcanic passive margins. C R Geosci $337: 13951408$ 
Gerya T, Yuen D, Maresch W (2004) Thermomechanical mod elling of slab detachment. Earth Planet Sci Lett 226:101 106

Gerya T, Connolly J, Yuen D, Gorczyk W, Capel A (2006) Seismic implications of mantle wedge plumes. Phys Earth Planet Int 156:59 74

Griffin WL, O'Reilly S, Afonso J, Begg G (2009) The composi tion and evolution of lithospheric mantle: a re evaluation and its tectonic implications. J Petrol 50:1185 1204

Green H, Dobrzhinetskaya L, Bozhilov K.N. (2000). Mineral ogical and experimental evidence for very deep exhumation from subduction zones. J. Geodyn., 30:61 76

Guillot S, Garzanti E, Baratoux D, Marquer D, Maheo G, Sigoyer J (2003) Reconstructing the total shortening history of the nw himalaya. Geochem Geophys Geosys 4:1064. doi:10.1029/2002GC000484

Haggerty S.E, Sautter V (1990) Ultradeep (greater than 300 kilometers), ultramafic upper mantle xenoliths. Science, 248:993 996

Hart SR, Hauri EH, Oschman LA, Whitehead JA (1992) Mantle plumes and entrainment: isotopic evidence. Science 256: 517520

Hebert L, Antoshechkina P, Asimow P, Gurnis M (2009) Emer gence of a low viscosity channel in subduction zones through the coupling of mantle flow and thermodynamics. Earth Planet Sci Lett 278:243 256

Hirschmann MM (2006) Water, melting, and the deep Earth's H2O cycle. Ann Rev Earth Planet Sci 34:629 653

Hirth G, Kohlstedt DL (2003) Rheology of the upper mantle and the mantle wedge: a view from the experimentalists. In: Eiler J (ed) Inside the subduction factory, vol 138, Geophysical monograph., pp 83105

Holland T, Powell R (1998) An internally consistent thermody namic data set for phases of petrological interest. J Metam Geol 16:309 343

Hyndman R, Peacock S (2003) Serpentinization of the forearc mantle. Earth Planet Sci Lett 212:417 432

Irifune T, Isshiki M (1998) Iron partitioning in a pyrolite mantle and the nature of the $410 \mathrm{~km}$ seismic discontinuity. Nature 392:702 705

Irifune T, Ringwood A, Hibberson W (1994) Subduction of continental crust and terrigenous and pelagic sediments: an experimental study. Earth Planet Sci Lett 126:351 368

Iwamori H, McKenzie D, Takahashi E (1995) Melt generation by isentropic mantle upwelling. Earth Planet Sci Lett 134:253 266

Jarvis G, McKenzie D (1980) Convection in a compressible fluid with infinite prandtl number. J Fluid Mech 96:515 583

Jordan TH (1978) Composition and development of the conti nental tectosphere. Nature 274:544 548

Karato S I (2008) Deformation of Earth materials: an introduc tion to the rheology of the solid Earth. Cambridge University Press, Cambridge, UK, 463 p

Katz RF, Spiegelman M, Langmuir C (2003) A new parameter ization of hydrous mantle melting. Geochem Geophys Geo syst 4(9):1073. doi:10.1029/2002GC000433

Keskin M (2007) Eastern Anatolia: a hotspot in a collision zone without a mantle plume. In: Foulger G, Jurdy D (eds) Plates, plumes and planetary processes. Geological Society of America Special Paper, vol 430. The Geological Society of America, pp 693 722, doi:10.1130/2007.2430
Kirby S.H., Kronenbrg A.K., (1987) Rheology of the litho sphere:selected topics. Rev. Geophys. 25:1219 1244

Kirby S.H. (1983) Rheology of the lithosphere. Rev. Geophys., 21:1458 1487

Kundu PK (1990) Fluid mechanics. Academic, California, USA

Lange R, Charmichael I (1987) Densities of Na2O, K2O, CaO, $\mathrm{MgO}, \mathrm{FeO}, \mathrm{Fe} 2 \mathrm{O} 3, \mathrm{Al} 2 \mathrm{O} 3, \mathrm{TiO} 2, \mathrm{SiO} 2$ liquids: new mea surements and derived partial molar properties. Geochim Cosmochim Acta 51(11):2931 2946

Lee C TA, Chen W P (2007) Possible density segregation of subducted oceanic lithosphere along a weak serpentinite layer and implications for compositional stratification of the earth's mantle. Earth Planet Sci Lett 255:357 366

Li Z, Gerya T (2009) Polyphase formation and exhumation of high to ultrahigh pressure rocks in continental subduction zone: numerical modeling and application to the Sulu ultra high pressure terrane in eastern china. J Geophys Res 114: B09406. doi:10.1029/2008JB005935

Liu L, Zhang J, Green H, Jin Z, Bozhilov K.N. (2007) Evidence of former stishovite in metamorphosed sediments, implying subduction to $>350 \mathrm{~km}$. Earth Planet. Sci. Lett., 263: 180191

Mackwell S.J., Zimmerman M.E., Kohlstedt D.L., (1998) High temperature deformation of dry diabase with application to tectonics on Venus. J. Geophys. Res. 103:975 984

McDonough WF, Sun S (1995) The composition of the Earth. Chem Geol 120:223 253

Miyajima N, Yagi T, Hirose K et al (2001) Potential host phase of aluminum and potassium in the earths lower mantle. Am Mineral 86:740 746

Moresi L, Dufur F, Mühlhaus H (2003) A lagrangian integration point finite element method for large deformation modeling of viscoelastic geomaterials. J Comp Phys 184:476 497

Nakagawa T, Tackley P, Deschamps F, Connolly J (2009) Incorporating self consistently calculated mineral physics into thermochemical mantle convection simulations in a $3 \mathrm{D}$ spherical shell and its influence on seismic anomalies in Earths mantle. Geochem Geophys Geosys 10:Q03004. doi:10.1029/2008GC002280

Nikolaeva K, Gerya T, Connolly J (2008) Numerical modelling of crustal growth in interoceanic volcanic arcs. Phys Earth Planet Int 171:336 356

Ono S (1998) Stability limits of hydrous minerals in sediment and mid ocean ridge basalt compositions: implications for water transport in subduction zones. J Geophys Res 103:18253 18267

Ono S (1999) High temperature stability limit of phase egg, AlSiO3(OH). Contrib Mineral Petrol 137:83 89

Patino Douce A, McCarthy T (1998) Melting of crustal rocks during continental collision and subduction. In: Hacker B, Liou J (eds) When continents collide. Dordrecht, Kluwer, pp 2755

Phipps Morgan J (2001) Thermodynamics of pressure release melting of a veined pudding mantle. Geochem Geophys Geosys 2, 2000GC000049

Pitzer K, Sterner S (1994) Equations of state valid continuously from zero to extreme pressures for h2o and co2. J Chem Phys 101(4):3111 3116

Plank T, Langmuir C (1998) The chemical composition of subducting sediment and its consequences for the crust and mantle. Chem Geol 145:325 394 
Ranalli G (1995) Rheology of the Earth, 2nd edn. Chapman \& Hall, London

Ranalli G, Pellegrini R, D’Offizi S (2000) Time dependence of negative buoyancy and the subduction of continental litho sphere. J Geodyn 30:539 555

Rapp R, Irifune T, Shimizu N, Nishiyama N, Norman MD, Inoue $\mathrm{T}$ (2008) Subduction recycling of continental sedi ments and the origin of geochemically enriched reservoirs in the deep mantle. Earth Planet Sci Lett 271:14 23

Reddy J, Gartling D (2000) The finite element method in heat transfer and fluid dynamics, 2nd edn. CRC Press, USA

Renshaw C, Schulson E (2004) Plastic faulting: brittle like failure under high confinement. J Geophys Res 109: B09207. doi:10.1029/2003JB002945

Ringwood AE (1982) Phase transformations and differentiation in subducted lithosphere: implications for mantle dynamics, basalt petrogenesis, and crustal evolution. J Geol 90:611 643

Rudnick RL, Gao S (2003) Composition of the continental crust. In: Rudnick RL, Holland HD, Turekian KK (eds) The crust, vol 3, Treatise on geochemistry. Elsevier, Oxford, pp 164

Scambelluri M, Pettke T, van Roermund H.L.M. (2008) Majori tic garnets monitor deep subduction fluid flow and mantle dynamics. Geology, 36:59 62

Schilling J, Zajac M, Evans R, Johnston T, White W, Devine J, Kingsley R (1983) Petrologic and geochemical variations along the Mid Atlantic Ridge from 29 degrees $N$ to 73 degrees N. Am J Sci 283:510 586

Schmidt M.W, Poli S (1998) Experimentally based water bud gets for dehydrating slabs and consequences for arc magma generation. Earth Planet. Sci. Lett., 163:361 379

Schubert G, Turcotte DL, Olson P (2001) Mantle convection in the Earth and planets. Cambridge University Press, Cambridge, UK

Sella GF, Dixon T, Mao A (2002) Revel: a model for recent plate velocities from space geodesy. J Geophys Res 107(B4), 2081, doi:10.1029/2000JB000033

Shimada M (1993) Lithosphere strength inferred from fracture strength of rocks at high confining pressures and tempera tures. Tectonophysics 217:55 64

Sobolev S, Babeyko A (2005) What drives orogeny in the Andes? Geology 33:617 620

Song S, Zhang L, Niu Y. (2004) Ultra deep origin of garnet peridotite from the North Qaidam ultrahigh pressure belt, Northern Tibetan Plateau, NW China. Am. Min., 89: 13301336

Takahashi N, Kodaira S, Tatsumi Y, Kaneda Y, Suyehiro K (2008) Structure and growth of the Izu Bonin Mariana arc crust: 1 seismic constraint on crust and mantle structure of the Mariana arcback arc system. J Geophys Res 113: B01104. doi:10.1029/2007JB005120

Tatsumi Y, Eggins S (1995) Subduction zone magmatism. Blackwell, Oxford, UK

Tirone M, Ganguly J, Morgan J (2009) Modeling petrological geodynamics in the Earths mantle. Geochem Geophys Geosys 10:Q04012. doi:10.1029/2008GC002168

Toussaint G, Burov E, Avouac J P (2005) Tectonic evolution of a continental collision zone: a thermomechanical numerical model. Tectonics, TC6003, doi:10.1029/2003TC001604
Turner S, Evans P, Hawkesworth C (2001) Ultrafast source to surface movement of melt at island arcs from 226ra 230th systematics. Science 292:1363 1366, doi: 10.1126/science. 1059904

van Keken P, Karato S I, Yuen D (1996) Rheological control of oceanic crust separation in the transition zone. Geophys Res Lett 23:1821 1824

Vry J, Powell R, Golden K, Petersen K (2009) The role of exhumation in metamorphic dehydration and fluid produc tion. Nat Geosci 3:31 35

Wark D, Williams C, Watson E, Price J (2003) Reassesment of pore shapes in microstructurally equilibrated rocks, with implications for permeability of the upper mantle. J Geophys Res 108:2050. doi:10.1029/2001JB001575

Warren C, Beaumont C, Jamieson RA (2008) Formation and exhumation of ultra high pressure rocks during conti nental collision: role of detachment in the subduction chan nel. Geochem Geophys Geosys 9(4). doi:10.1029/ 2007GC001839

Woodland A, Angel R (1997) Reversal of the orthoferrosilite high $\mathrm{P}$ clinoferrosilite transition, a phase diagram for FeSiO3 and implications for the mineralogy of the Earth's upper mantle. Eur J Mineral 9:245 254

Workman R, Hart S, Jackson M, Regelous M, Farley KA, Blusztajn J, Kurz M, Staudigel H (2004) Recycled metaso matized lithosphere as the origin of the Enriched Mantle II (EM2) end member: evidence from the Samoan volcanic chain. Geochem Geophys Geosyst 5, Q04008, doi:10.1029/ 2003GC000623

Wu Y, Fei Y, Jin Z, Liu X (2009) The fate of subducted upper continental crust: an experimental study. Earth Planet Sci Lett 282:275 284

Xu W, Lithgow Bertelloni C, Stixrude L, Ritsema J (2008) The effect of bulk composition and temperature on mantle seis mic structure. Earth Planet Sci Lett 275:70 79

Yamato P, Agard P, Burov E, Le Pourhiet L, Jolivet L, TiberiBurov C (2007) Burial and exhumation in a subduc tion wedge: mutual constraints from thermomechanical modeling and natural $\mathrm{P} \mathrm{T} \mathrm{t}$ data (schistes lustrs, western alps). J Geophys Res 112:B07410. doi:10.1029/ 2006JB004441

Yamato P, Burov E, Agard P, Le Pourhiet L, Jolivet L (2008) HP UHP exhumation during slow continental subduction: self consistent thermodynamically and thermomechanically coupled model with application to the western alps. Earth Planet Sci Lett 271:63 74

Ye K, Cong B, Ye D (2000) The possible subduction of conti nental material to depths greater than $200 \mathrm{~km}$. Nature, 407:734 736

Yoshioka S, Wortel M (1995) 3D numerical modeling of detachment of subducted lithosphere. J Geophys Res 100 (20):223 244

Zang SX, Weia R, Ninga J (2007) Effect of brittle fracture on the rheological structure of the lithosphere and its application in the ordos. Tectonophysics 429:267 285

Zhai S, Ito E (2008) Phase relations of CaAl4Si2O11 at high pressure and high temperature with implications for sub ducted continental crust into the deep mantle. Phys Earth Planet Int 167(3 4):161 167 